\title{
JGA Keynote Program \\ The 5th International \\ Gastrointestinal Consensus Symposium (IGICS)
}

\section{Chronic Inflammation and Cancer}

February 11, 2012, Sendai, Japan

\section{Abstracts}

Guest Editor

Yoshikazu Kinoshita, Izumo

\section{Contents}

Outline

Welcome Address

Program

Special Lecture

Oral Sessions

Oral Session 1

Abstracts 0-1-1-0-1-3

Oral Session 2

Abstracts 0-2-1-0-2-5

Oral Session 3

Abstracts 0-3-1-0-3-6

Oral Session 4

Abstracts 0-4-1-0-4-5

Oral Session 5

Abstracts 0-5-1-0-5-5

\section{Poster Sessions}

Poster Session 1

Abstracts P-1-1-P-1-6

Poster Session 2

Abstracts P-2-1-P-2-6

Poster Session 3

Abstracts P-3-1-P-3-5

Poster Session 4

Abstracts P-4-1-P-4-6

Poster Session 5

Abstracts P-5-1-P-5-6

Author Index 


\section{Outline}

Digestion

\section{JGA Keynote Program \\ The 5th International Gastrointestinal Consensus Symposium (IGICS)}

Date February 11 (Sat.), 2012

Time 08:40-16:50

Venue Koyo Grand Hotel, Sendai, Japan

\section{IGICS Committee Members}

JGA International Exchange Committee Members

Yoshikazu Kinoshita, Japan (Chairperson of the 5th IGICS)

Shin Fukudo, Japan

Takashi Joh, Japan

Hidekazu Suzuki, Japan

Shin'ichi Takahashi, Japan

Fumiaki Ueno, Japan

Collaborators

Tetsuo Arakawa, Japan

Takayuki Matsumoto, Japan

Yuji Naito, Japan

IGICS International Active Members

Ki-Baik Hahm, Korea

Udom Kachintorn, Thailand

Abdul Aziz Rani, Indonesia

Jose D. Sollano, Philippines

Qi Zhu, China 
Dear Esteemed Colleagues,

It is our great pleasure to welcome you to the 5th International Gastrointestinal Consensus Symposium (IGICS) to be held on Saturday, February 11, 2012 in Sendai as a JGA Keynote Program during the 8th Annual Meeting of the Japanese Gastroenterological Association (February 10-11, 2012: President Prof. Michio Hongo of Tohoku University Faculty of Medicine).

The topic for the 5th IGICS is "Chronic inflammation and Cancer". The pathogenesis of gastrointestinal cancers has been intensively investigated, and the role of chronic inflammation as a mechanism of carcinogenesis has been increasingly recognized. Chronic inflammation is particularly a key factor for the development of Barrett's adenocarcinoma, Helicobacter pylori infection related gastric carcinoma, and inflammatory bowel disease-related colonic carcinomas. This symposium will focus on the pathogenesis, prevention, diagnosis, and treatment of these chronic inflammation- related gastrointestinal cancers in Asia.

One objective of this symposium is to foster the academic development of young gastroenterologists from all over the world, and to increase international exchange. It is our sincere hope that you will attend the symposium, as we believe it will be greatly enriched by your active participation in the discussion. We will present the IGICS Award for several excellent papers presented by young investigators.

I look forward to seeing you in Sendai, the city that suffered damage from the recent big earthquake but is now well on its way to recovering from the disaster, in February 2012. You will be able to benefit from and experience both high quality scientific discussion and the silent, tranquil beauty of Sendai.

With warm regards,

Yoshikazu Kinoshita, MD, PhD Chairperson of the 5th IGICS 


\section{Saturday, February 11, 2012}

08:40-08:45 Opening Remarks
Dr. Yoshikazu Kinoshita, Shimane University School of Medicine, Japan

08:45-09:10 0-1- Oral Session 1 - Esophagus

Chairpersons: Dr. Hidekazu Suzuki, Keio University School of Medicine, Japan

Dr. Ari F. Syam, University of Indonesia Cipto Mangunkusumo Hospital, Indonesia

1 ESD FOR BARRETT ESOPHAGEAL ADENOCARCINOMA

Dr. Akiko Takahashi, Saku Central Hospital, Japan

2 FXR ACTIVATION PROMOTES CDX2 DEGRADATION VIA THE UBIQUITIN-PROTEOSOME SYSTEM WITH UPREGULATION OF microRNA-221/222 IN HUMAN ESOPHAGEAL CELLS

Dr. Juntaro Matsuzaki, Keio University School of Medicine, Japan

3 TRYPSIN BUT NOT ACID IMPAIRED EPITHELIAL BARRIER FUNCTION AND INDUCED IL-8 SECRETION USING A STRATIFIED SQUAMOUS EPITHELIAL MODEL Dr. Jing Shan, Hyogo College of Medicine, Japan

09:10-09:50 O-2- Oral Session 2 - Stomach

Chairpersons: Dr. Hiroto Miwa, Hyogo College of Medicine, Japan

Dr. Qi Zhu, Rui Jing Hospital, Shanghai Jiao Tong University School of Medicine, China

1 DOWNREGULATION OF miR-200 FAMILY CAN BE A REASON FOR H. PYLORI-ASSOCIATED GASTRITIS Dr. Kayoko Matsushima, Nagasaki University, Japan

2 PREVENTION OF HELICOBACTER PYLORI-ASSOCIATED GASTRIC INFLAMMATION AND CONSEQUENT CARCINOGENESIS WITH NATURAL PRODUCTS

Dr. Eun-Hee Kim, Gachon University of Medicine and Science, Korea

3 S-ALLYLCYSTEINE FOR AMELIORATION OF GI INFLAMMATION: ANTI-INFLAMMATION BASED ON HDAC INHIBITION AND ANTIOXIDATION

Dr. Ki Seok Choi, Gachon University of Medicine and Science, Korea

4 DIFFERENT TIME POINT OF PROBIOTIC INTERFERES IMPROVE THE ERADICATION RATE OF TRIPLE THERAPY ON HELICOBACTER PYLORI: A MULTICENTER RANDOMIZED CONTROLLED STUDY IN SHANGHAI

Dr. Yiqi Du, Changhai Hospital, Second Military Medical University, China

5 ERCP VIA PEG HOLE

Dr. Takao Endo, Sapporo Shirakaba-dai Hospital, Japan

09:50-10:40 0-3- Oral Session 3 - Stomach

Chairpersons: Dr. Takashi Joh, Nagoya City University Graduate School of Medical Sciences, Japan

Dr. Jose D. Sollano, University of Santo Tomas, Philippines

1 SEROCONVERSION RATES OF HELICOBACTER PYLORI INFECTION IN KOREAN ADULTS

Dr. Jihoon Jung, Ulsan Collage of Medicine, Asan Medical Center, Korea

2 AN OPTICAL DIAGNOSIS FOR GASTRIC CANCER USING FLUORESCENCE OBSERVATION Dr. Tsuyoshi Kaneko, University of Tsukuba, Japan

3 EFFECT OF ERADICATION OF HELICOBACTER PYLORI ON RECURRENCE AFTER ENDOSCOPIC MUCOSAL RESECTION OF GASTRIC ADENOMA AND EARLY GASTRIC CANCER 
4 DOSE TRANSNASAL ENDOSCOPY FOR PERCUTANEOUS ENDOSCOPIC GASTROSTOMY

DECREASE LOCAL INFECTION?

Dr. Tomoko Koide, Yokohama City University Hospital, Japan

5 REBAMIPIDE EFFECT ON CHRONIC GASTRITIS IN DYSPEPTIC PATIENT: SYMPTOMS, ENDOSCOPIC AN HISTOLOGICAL EVALUATION

Dr. Ari Fahrial Syam, Faculty of Medicine, University of Indonesia, Indonesia

6 PROTECTIVE EFFECT OF REBAMIPIDE FOR FREE RADICALS IN PATIENTS WITH CHRONIC GASTRITIS Dr. Marcellus Simadibrata, Faculty of Medicine, University of Indonesia, Indonesia

\begin{tabular}{ll} 
10:40-11:00 & Report \\
& Chairperson: Dr. Yoshikazu Kinoshita, Shimane University School of Medicine, Japan \\
\hline
\end{tabular}

DIAGNOSIS AND TREATMENT OF BARRETT'S ESOPHAGUS IN ASIA

Dr. Norihisa Ishimura, Shimane University School of Medicine, Japan

\begin{tabular}{ll}
\hline 11:00-11:30 & Special Lecture \\
Chairperson: Dr. Tetsuo Arakawa, Osaka City University, Graduate School of Medicine, Japan
\end{tabular}

CONNECTION BETWEEN INFLAMMATION AND CARCINOGENESIS; CLUE FOR PREVENTION

Dr. Ki-Baik Hahm, Gachon University of Medicine and Science, Korea

p. 150

14:30-15:10 O-4- Oral Session 4 - Intestine and Colon

Chairpersons: Dr. Shin Fukudo, Tohoku University School of Medicine, Japan

Dr. Udom Kachintorn, Siriraj Hospital Mahidol University, Thailand

1 THE INFLUENCE OF BILATERAL ADRENALECTOMY ON INDOMETHACIN INDUCED SMALL INTESTINAL LESIONS IN RATS

Dr. Melinda Gyenge, Kyoto Pharmaceutical University, Japan

2 PROTECTIVE EFFECTS OF VARIOUS IMMUNONUTRIENTS AGAINST GUT ISCHEMIA/REPERFUSION INJURY IN RATS

Dr. Takashi Kohtani, Uwajima Municipal Yoshida Hospital, Japan

3 THE EFFECT OF METASTASIS INHIBITION INDUCED BY PICROPODOPHYLLIN IN COLON CANCER Dr. Xiaoying Feng, The Second Affiliated Hospital of Dalian Medical University, China

4 ROLE OF MILK FAT GLOBULE-EPIDERMAL GROWTH FACTOR 8 IN DEVELOPMENT OF COLITIS-ASSOCIATED CANCER

Dr. Ryusaku Kusunoki, Shimane University Faculity of Medicine, Japan

5 THE ROLE OF MINIPROBE SONOGRAPHY IN THE SEVERITY ASSESSMENT AND PREDICTION OF REMISSION OF UNCREATIVE COLITIS

Dr. Duanmin Hu, Rui Jin Hospital, Shanghai Jiaotong University School of Medicine, China

15:10-15:50 O-5- Oral Session 5 - Intestine and Colon

Chairpersons: Dr. Fumiaki Ueno, Ofuna Chuo Hospital, Japan

Dr. Takayuki Matsumoto, Hyogo College of Medicine, Japan

1 EXPERIMENTAL STUDY ON SYK GENE TRANSFECTION TO HUMAN COLON CANCER CELL LINES Dr. Yu Qing-Gong, Zhongshan Hospital of Dalian University, China

2 SONIC HEDGEHOG AS PATHOGENIC CONTRIBUTION TO COLITIS-ASSOCIATED CANCER AND PREVENTION WITH INHIBITORS OF Shh

Dr. Yoon Jae Kim, Gachon University Gil Medical Center, Korea

3 THE BACKGROUND OF COLITIS-ASSOCIATED CANCER OF UC PATIENTS

Dr. Kazuhiko Uchiyama, Kyoto Prefectural University of Medicine, Japan

4 A NEW CLASS OF NON-CODING RNAs WITH REGULATED TRANSCRIPTION AND DISEASE-SPECIFIC EXPRESSION PROFILES IN COLORECTAL CANCER

Dr. Sang Kil Lee, Yonsei University College of Medicine, Korea

5 THE EXPRESSION OF SURVIVIN IN COLORECTAL CARCINOGENESIS AND THE RELATIONS WITH CLINICOPATHOLOGIC CHARACTERISTICS

Dr. Lian-Jie Lin, The Shengjing Hospital of China Medical University, China 


\section{6:00-16:50 P-1- Poster Session 1}

Chairperson: Dr. Shin'ichi Takahashi, Kyorin University School of Medicine, Japan

1 PROTEIN EXPRESSIONS OF EGFR, K-ras, P53 AND Ki-67 IN COLORECTAL CANCER, GASTRIC CANCER AND ESOPHAGEAL CANCER

Dr. Lina Liu, First Affiliated Hospital of Dalian Medical University, China

2 A RETROSPECTIVE STUDY FOR INCIDENCE AND CLINICAL OUTCOMES OF HOSPITAL-ACQUIRED PNEUMONIA AFTER ENDOSCOPIC SUBMUCOSAL DISSECTION

Dr. Chan Hyuk Park, Yonsei University College of Medicine, Korea

3 THE ROLE OF SERUM PEPSINOGEN IN THE DIAGNOSIS OF GASTRIC DISEASES

Dr. Zhang Xiao-mei, Xiangya Hospital, Central South University, China

4 CHARACTERISTICS OF RECURRENT EARLY GASTRIC CANCER AFTER ENDOSCOPIC RESECTION OF EARLY GASTRIC CANCER

Dr. Takatsugu Yamamoto, Teikyo University School of Medicine, Japan

5 SERUM PEPSINOGEN TEST AND DYSPEPSIA MANAGEMENT: AN INVESTIGATION ON DIAGNOSTIC ACCURACY IN CLINICAL SETTING

Dr. Hong Ouyang, The People's Hospital of Lin'an City, China

6 EFFECTS OF CELECOXIB ON CELL APOPTOSIS IN HUMAN GASTRIC CANCER CELL LINE BGC-823 AND EXPRESSIONS OF Fas, FasL AND Bcl-2

Dr. Li Qian, Xiangya Hospital, Central South University, China

\section{6:00-16:50 P-2- Poster Session 2}

Chairperson: Dr. Ken Haruma, Kawasaki Medical School, Japan

1 ING1 PLAYS AN IMPORTANT ROLE IN REGULATING AGS CELL APOPTOSIS BY DOWN-REGULATED CASPASE 2 GENE EXPRESSION

Dr. Xiang-Min He, The First Affiliated Hospital, China Medical University, China

2 COMPARISON OF ESD PERFORMANCE UNDER INTERMITTENT MIDAZOLAM INJECTION AND PROPOFOL CONTINUOUS INFUSION: RETROSPECTIVE STUDY

Dr. Jae Hun Min, Yonsei University College of Medicine, Korea

3 NATURAL COURSE OF NON-CURATIVE ENDOSCOPICALLY RESECTED DIFFERENTIATED EARLY GASTRIC CANCER

Dr. Ji Yong Ahn, University of Ulsan College of Medicine, Asan Medical Center, Korea

4 SURVIVIN, CASPASE-3 PROTEIN EXPRESSION IN GASTRIC CANCER TISSUE Dr. Xiuying Xu, The First Affiliated Hospital, China Medical University, China

5 CHARACTERISTICS OF ENDOSCOPIC FINDING IN GASTRIC ADENOMA WITH HIGH GRADE DYSPLASIA SUGGESTING GASTRIC CANCER Dr. Jung Ho Kim, Gachon University Gil Medical Center, Korea

6 COEXISTENCE OF ULCERATIVE COLITIS AND IRON DEFICIENCY ANEMIA WITH HEPATITIS C VIRUS-RELATED CRYOGLOBULINEMIA: A CASE REPORT AND LITERATURE REVIEW Dr. Yu-hong Huang, The First Affiliated Hospital, China Medical University, China

1 ANALYSIS THE STATUS QUO OF THE DIAGNOSIS AND TREATMENT OF 81 PATIENTS WITH PRIMARY GASTROINTESTINAL LYMPHOMA

Dr. Feng LiJuan, Xiangya Hospital, Central South University, China

2 EFFECTIVENESS OF DAIKENCHUTO, A TRADITIONAL JAPANESE HERBAL MEDICINE, IN ACCELERATING CAPSULE ENDOSCOPY TRANSIT TIME - A PROSPECTIVE PILOT STUDY

Dr. Konosuke Nakaji, Aishinkai Nakae Hospital, Japan

3 PROTEIN LOSING ENTEROPATHY IN SYSTEMIC LUPUS ERYTHEMATOSUS: A CASE REPORT AND REVIEW OF THE LITERATURE

Dr. Tian Feng, Sheng Jing Hospital of China Medical University, China

4 INVESTIGATE DIAGNOSIS AND TREATMENT OF RECTAL CARCINOID TUMORS 
5 THE SUCCESSFUL ATTEMPT TO PERFORM ESD FOR LOW GRADE DYSPLASIA IN PATIENTS WITH ULCERATIVE COLITIS

Dr. Kenichi Morimoto, Osaka City University, Japan

1 STUDY ON THE EFFICACY AND MECHANISM OF ACTION OF PROBIOTIC BACTERIA VSL\#3 ON THE MODEL OF EXPERIMENTAL COLITIS OF RATS

Dr. Min-Jiang, First Affiliated Hospital of China Medical University, China

2 IDENTIFICATION OF ABERRANTLY EXPRESSED microRNAs IN RECTAL CANCER AND ITS CLINICAL SIGNIFICANCE

Dr. Xinhua Li, Xiangya Hospital, Central South University, China

3 EXPRESSION OF TRANSFORMING GROWTH FACTOR $\beta$ RECEPTOR II IN COLORECTAL CANCER AND ITS RELATIONSHIP TO CYCLIND,

Dr. Wang Zhaohui, Dalian Municipal Central Hospital, China

4 HUMAN UMBILICAL CORD MESENCHYMAL STEM CELLS AMELIORATE MICE COLITIS BY REGULATING THE BALANCE OF Th1/Th2 AND Tregs/Th17 Dr. Yan Lin, Shengjing Hospital of China Medical University, China

5 INTRAVENOUS INJECTION OF BONE MORPHOGENETIC PROTEIN IN THE TREATMENT OF DSS-INDUCED COLITIS

Dr. Weixin Liu, The 1st Affiliated Hospital, China Medical University, China

6 DIAGNOSTIC VALUE OF SIMULTANEOUS DETERMINATION OF TUMOR MARKERS IN ASCITIC FLUID AND SERUM AND THEIR RATIOS FOR DIFFERENTIATION BENIGN FROM MALIGNANT ASCITES Dr. Xu Mei-hua, Xiangya Hospital, Central-South University, China

16:00-16:50 P-5- Poster Session 5

Chairperson: Dr. Kenji Furuta, Shimane University School of Medicine, Japan

1 BONE MORPHOGENIC PROTEIN-7 (BMP-7) OPPOSES THE FIBROGENIC ACTIVITY OF TGF- $\beta 1$ ON RAT MODEL OF LIVER FIBROSIS

Dr. Lan Zhong, East Hospital of Tongji University School of Medicine, China

2 STUDY ON INTRATUMOR INJECTION OF OCTREOTIDE TEMPERATURE-SENSITIVE GEL FOR THE TREATMENT OF LIVER CANCER IN MOUSE

Dr. Zhijun Duan, First Affiliated Hospital of Dalian Medical University, China

3 COMPARISON OF ENDOSCOPIC PAPILLARY LARGE BALLOON DILATION AND ENDOSCOPIC SPHINCTEROTOMY FOR RETRIEVAL OF CHOLEDOCHOLITHIASIS: A META-ANALYSIS OF RANDOMIZED CONTROLLED TRIALS

Dr. Yadong Feng, The First Affiliated Hospital of Nanjing Medical University, China

4 AN EOSINOPHILIC CHOLANGITIS CASE REPORT WITH A REVIEW OF ASSOCIATED LITERATURES Dr. Haoqing, Shengjing Hospital Affiliated to China Medical University, China

5 THE RELATION BETWEEN HUMAN PAPILLOMAVIRUS AND PANCREATIC CARCINOMA Dr. Gao Ming-yu, Liaoning Electric Power Central Hospital, China

6 THE ANALYSIS OF LIVER CIRRHOSIS BLOOD LIPIDS

Dr. Jingchi, The First Affiliated Hospital, China Medical University, China 


\section{Connection Between Inflammation and Carcinogenesis; Clue for Prevention}

\author{
Ki Baik Hahm, Eun Hee Kim, Yoon Jae Kim, Jung Ho Kim, \\ Ki Seok Choi, Hua Hong, Kyung Sook Hong, Young Min \\ Han, Ju Hyun Kim
}

Department of Gastroenterology, Gachon University Gil

Medical Center and Lab of Translational Medicine, Lee Gil

ya Cancer and Diabetes Institute, Incheon, Korea

The crosslink between inflammation and carcinogenesis is exemplified with colitis-associated accompanied with the examples that successful achievement of cancer prevention with TNF-a antibody, potent anti-inflammatory action of proton pump inhibitor, and novel anti-inflammatory agent, $8-\mathrm{OHdG}$ and SAC (S-allyl cysteine) in this special lecture of IGICS. The emergence of infliximab was epochal event in the treatment of inflammatory bowel disease (IBD). Since colitis-associated cancers arose in the setting of chronic inflammation, during which "inflammation-dysplasia-carcinoma" prevails and anti-inflammatory agents can prevent carcinogenesis, we hypothesized whether infliximab can prevent colitic cancer in animal models, for which C57BL/6 mice were exposed to 15 cycles of dextran sulfate sodium (DSS) with each cycle consisting of $0.7 \%$ DSS for 1 week followed by sterilized water for 10 days. Infliximab, $4 \mathrm{mg} / \mathrm{kg} i v$, was given on $1^{\text {st }}, 3^{\text {rd }}$, and $7^{\text {th }}$ week or $25^{\text {th }}, 27^{\text {th }}$, and $31^{\text {th }}$ week of cycle according to "step-up" versus "top-down" strategy. Molecular change about inflammation and carcinogenesis were compared between groups. Multiple colorectal tumors developed in $75-80 \%$ of control mice, whereas only $16.7 \%$ of mice treated with $1^{\text {st }}, 3^{\text {rd }}$, and $7^{\text {th }}$ weeks of infliximab developed colon tumors. Significant decreases in TNF- $\alpha$ level, mast cell number, and the expression of inflammatory cytokines were observed in "top-down" strategy using infliximab. The expression and activity of MMP-9 and MMP-11 were significantly decreased in mice treated with infliximab accompanied with attenuated numbers of "beta-catenin accumulated crypts". In animal group where infliximab was administered at later stage of $25^{\text {th }}, 27^{\text {th }}$, and $31^{\text {th }}$ weeks, no reduction in tumorigenesis was noted. These biological effects of infliximab were further explored in in vitro experiment using Raw 264.7 and Jurkat T cells. Conclusively, earlier and intensive therapy with infliximab should be considered for either mitigating clinical course or preventing ultimate development of colitic cancer in high risk IBD patients. Based on our previous findings that proton pump inhibitor can impose significant levels of anti-inflammatory, anti-angiogenic, and selective apoptosis induction beyond gastric acid suppression, we investigated whether omeprazole (OMP) can prevent the development of colitis-associated cancer in a mouse model induced by repeated bouts of colitis. OMP, $10 \mathrm{mg} / \mathrm{kg}$, was given ip all through the experimental periods for colitis-associated carcinogenesis. Molecular changes regarding inflammation and carcinogenesis were compared between control group and colitis cancer group treated with OMP in addition to chemopreventive outcome. 9 of $12(75.0 \%)$ in control group developed multiple colorectal tumors, whereas tumors were noted in only 3 of $12(25.0 \%)$ mice treated with daily injection of OMP. Significant induction of apoptosis was observed in tumor tissue treated with OMP. OMP could block the trophic effect of gastrin in colon epithelial cells. Significant anti-inflammatory, anti-oxidative, and anti-mutagenic activities of OMP played cancer preventive role against colitis induced carcinogenesis, novel in vivo evidence suggestive of chemopreventive action independent on gastric acid suppression. Another promising result was drawn from the administration of 8-OHdG, paradoxical antioxidative substance.

\begin{tabular}{ll}
\hline KARGER & (c) 2012 S. Karger AG, Basel \\
Fax +41613061234 & $0012-2823 / 12 / 0852-0143 \$ 38.00 / 0$ \\
$\begin{array}{l}\text { E-Mail karger@karger.ch } \\
\text { www.karger.com }\end{array}$ & $\begin{array}{l}\text { Accessible online at: } \\
\text { www.karger.com/dig }\end{array}$
\end{tabular}




\section{Oral Sessions}

Digestion

\section{Oral Session 1 - Esophagus}

Chairpersons: Hidekazu Suzuki, Ari F. Syam

\section{0-1-1}

\section{ESD for Barrett Esophageal Adenocarcinoma}

\section{Akiko Takahashi, Tsuneo Oyama \\ Gastroenterology, Saku Central Hospital, Saku, Japan}

Introduction: ESD for Barrett esophageal adenocarcinoma (BEA) is difficult, because the esophageal lumen is narrow and there is a lot of fibrosis in the submucosal layer. Purpose of our study is to clarify the safety and efficiency of ESD for BEA.

Methods: Twenty-seven patients ( 24 males and 3 females) with 34 lesions of superficial BEA were treated by ESD from January 2000 to December 2010. We examined outcome of ESD. The median age was 67 (range: 32-83). The median follow-up period was 35 months. The median diameter of the lesions was 14 (range: 2-94). The median diameter of resected specimen was 45 (range: 19-134) mm. Invasion depth was SMM 23\%, LPM 9\%, DMM 47\%, SM1 9\% and SM2 12\%. SM1 was defined as submucosal invaded cancer with 200 micrometer or less.

Result: 1 . The en-bloc resection rate was $100 \%$. The $\mathrm{R} 0$ resection rate (En bloc resection, lateral and vertical margin was negative) was $94 \%$ (32/34). Local recurrence rate was $2.9 \%$ (1/34). The case was treated by re-ESD.

2. The duration of ESD was 124 (range: 50-405) minutes. The bleeding during ESD could be controlled by hemostatic forceps, and no patients required blood transfusion. Perforation rate during ESD was $0 \%$ and delayed perforation rate was $2.9 \%(1 / 34)$.

3. Ilb extension was $18 \%$. Metachronous cancer of esophagus was $22 \%$, and that of other organ was $8 \%$.

4. Lymph node metastasis, distant metastasis, died of BEA and treatment related death in M to SM1 was $0 \%$. That of SM 2 was $75 \%$, $25 \%, 25 \%$ and $25 \%$, respectively.

Conclusion: ESD is an useful treatment for BEA The prognosis of BEA was excellent when the invasion depth was M or SM1. However, that of SM2 was poor. Therefore, additional therapy should be performed for SM2 patients.

\section{0-1-2 \\ FXR Activation Promotes CDX2 Degradation via the Ubiquitin-Proteosome System with Upregulation of microRNA-221/222 in Human Esophageal Cells}

\author{
Juntaro Matsuzaki ${ }^{1}$, Hidekazu Suzuki', Hitoshi Tsugawa', \\ Yoshimasa Saito², Sharif Hossain ${ }^{3}$, Toshihiro Akaike?, \\ Mitsuhiro Watanabe ${ }^{4}$, Toshifumi Hibi ${ }^{1}$ \\ 'Division of Gastroenterology and Hepatology, \\ Department of Internal Medicine, Keio University \\ School of Medicine, Tokyo, Japan, ${ }^{2}$ Division of \\ Pharmacotherapeutics, Keio University Faculty of \\ Pharmacy, Tokyo, Japan, ${ }^{3}$ Department of Biomolecular \\ Engineering, Tokyo Institute of Technology Graduate \\ School of Biosciences and Biotechnology, Yokohama, \\ Japan, ${ }^{4}$ Division of Endocrinology, Metabolism and \\ Nephrology, Department of Internal Medicine, Keio \\ University School of Medicine, Tokyo, Japan
}

Introduction: Bile reflux and the degradation of CDX2 might be associated with the malignant transformation of Barrett's esophagus to adenocarcinoma. The aim of this study is to investigate whether bile acid and $m i R-221 / 222$ might affect the degradation of CDX2 and proliferation of human esophageal cells.

Methods: Using human esophageal squamous epithelial cells (HET-1A) transfected with CDX2 expression vector (HET1A+Cdx2) and HET1A with control vector (HET1A+mock), the expression of $\mathrm{CDX} 2$ and $\mathrm{p} 27^{\mathrm{Kip} 1}$ protein and $m i R-221 / 222$ during the exposure to cholic acid (CA) and FXR agonist (GW4064) were evaluated by western blotting and quantitative RT-PCR. Cell proliferation during the exposure to bile was determined by BrdU ELISA.

Result: Cell proliferation was decreased by the transfection with CDX2. However, cell proliferation of HET1A $+\mathrm{Cdx} 2$ was increased by the exposure to CA, whereas cell proliferation of HET1A+ mock was not affected by CA. In HET1A $+\mathrm{Cdx} 2$, the protein expression of CDX2 was decreased in a dose-dependent manner during the exposure to CA. The expression of $m i R-221 / 222$ was increased and that of p $27^{\mathrm{Kip} 1}$ protein was decreased by the exposure to CA in HET1A $+\mathrm{Cdx} 2$, but not in HET1A+mock. The mRNA expression of FXR was increased in HET1A $+\mathrm{Cdx} 2$. FXR agonist enhanced the expression of $m i R-221 / 222$ and the degradation of CDX2. Pre-miR-221/222 precursors enhanced the degradation of CDX2. Anti-miR-221/222 inhibitors or proteasome inhibitors (MG132 and Lactacystin) restored the degradation of CDX2 derived from the exposure to CA.

Conclusion: The degradation of $\mathrm{CDX} 2$ and cell proliferation were enhanced by the activation of FXR and the increased expression of $m i R-221 / 222$ in human esophageal epithelial cells. This pathway might play a role in the transformation from Barrett's esophagus to adenocarcinoma.

\section{KARGER \\ (C) 2012 S. Karger AG, Basel}

Fax +4161306 1234

E-Mail karger@karger.ch

www.karger.com 


\section{0-1-3 \\ Trypsin But Not Acid Impaired Epithelial Barrier Function and Induced IL-8 Secretion Using a Stratified Squamous Epithelial Model \\ Jing Shan, Tadayuki Oshima, Noriko Kamiya, Masayo Togawa, Hirokazu Fukui, Jiro Watari, Hiroto Miwa \\ Division of Upper Gastroenterology, Department of Internal Medicine, Hyogo College of Medicine, Japan}

Introduction: Immune-mediated mechanisms have been suggested to involve in the development of GERD, and IL- 8 may have a central role in this mechanism. Up-regulation of IL-8 was verified via protease-activated receptors 2 (PAR2) pathway in esophagus epithelia cells. Esophageal barrier can defend various stimuli from refluxate which results in GERD. However, this property has been ignored in previous studies basing on monolayer cells. In the present study, we established a stratified squamous epithelial model to exam IL-8 secretion and PAR2 activation by a synthesized PAR2 agonist (SLIGKV-NH2), trypsin (a nature PAR2 agonist) and acidic conditions.

Methods: NHBE (normal human bronchial epithelial) cells were cultured in Transwell ${ }^{\text {TM}}$-Clear wells by air-liquid interface (ALI) culture to establish a stratified squamous epithelial model in vitro.

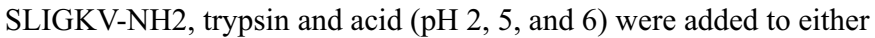
apical or basolateral compartment by continuous stimulation for 24 hours or by interval stimulation ( $10 \mathrm{~min}, 3$ times/day) for 5 days to evaluate their influence on IL-8 production and trans-epithelial electrical resistance (TEER).

Result: Trypsin significantly increased IL- 8 secretion by epithelial cell layers accompanied with the significant decrease of TEER. SLIGKV-NH2 didn't affect the TEER and IL-8 production by apical stimulation, but significantly upregulated IL- 8 production by basolateral stimulation without affecting the TEER, suggesting PAR2 activation might occur in unkeratinized basal or suprabasal layers in stratified squamous epithelial model. Trypsin but not acid in 5 days interval stimulation induced significant decrease of TEER and significant increase of IL-8 secretion.

Conclusion: Trypsin-induced IL-8 secretion occurred with the impairment of epithelial barrier function. Trypsin rather than acid may be one of the initial factors for the barrier destruction, followed by the activation of PAR2-IL8 pathway and chronic inflammatory vicious circle. Reflux of trypsin should be considered as a potential initial factor of GERD.

\section{Oral Session 2 - Stomach}

Chairpersons: Hiroto Miwa, Oi Zhu

0-2-1

Downregulation of miR-200 Family Can Be a
Reason for $H$. pylori-Associated Gastritis

Kayoko Matsushima1, Hajime Isomoto', Yuko Akazawa1, Naoyuki Yamaguchi', Ken Ohnita', Tatsuki lchikawa', Toshiyuki Nakayama², Tomayoshi Hayashi², Fuminao Takeshima', Toshiya Hirayama ${ }^{3}$, Kazuhiko Nakao ${ }^{1}$

${ }^{1}$ Department of Gastroenterology and Hepatology,

${ }^{2}$ Pathology, ${ }^{3}$ Bacteriology Nagasaki University, Nagasaki, Japan

Introduction: The functional roles of miRNAs remain unclear in $H$. pylori-associated gastritis (HAG). In our recent study, miRNAs expression profile in HAG from 55 patients. In the current study, we focused on miR-200 family (miR-141,-200a, -200b, -200c, -429) which were downregulated in HAG. ZEB-1,-2, known as inhibitors of E-cadhein, are possible targets of miR-200 family according to those sequence complementarity.

Methods: Using 53 biopsy samples, the association of their miRNA levels with the histopathological findings in accordance with the updated Sydney system was examined. Additional biopsy samples were obtained to examine their correlation with the expression levels of representative inflammatory factors (IL- $8, T N F \alpha$, TGF $\beta, H G F$ ) by qRT-PCR. As a functional analysis of migration capacity, wound healing assay was conducted using gastric cancer cell line (AZ-521) after transfection of miR-200 family precursors. By reporter gene assays, we examined ZEB1-3'-UTR-luciferase activity with co-transfection of the reporter plasmid along with each miR-200 family precursor.

Result: Expression of miR-200 family was restored after $H$. pylori eradication. Expression levels of miR-200 family significantly correlated with histopathological HAG scores, inflammatory factors. In AZ-521 cells, the expression levels of miR-200 family negatively correlated with ZEB-1, -2 but positively correlated with E-cadherin RNA expression levels. In wound healing assay, miR-429 precursor inhibited the migration capacity after $24 \mathrm{hrs}$. miR-429 precursor significantly reduced ZEB1-3'-UTR-luciferase activity. Of note, the expression of miR-200 family was recovered by demethylation agent, 5-aza-2'-deoxycytidine in AZ-521 cells, suggesting the miRNAs expression might be modulated by DNA methylation.

Conclusion: The results provide insights into miR-200 family involvement in the pathogenesis of HAG. The miR-200 family expression might be silenced via DNA methylation. Downregulation of miR-200 family in particular miR-429 can lead to disrupted cell arraignment by targeting ZEB-1 in gastric mucosa. 


\section{0-2-2 \\ Prevention of Helicobacter pylori-Associated Gastric Inflammation and Consequent Carcinogenesis with Natural Products}

Eun-Hee Kim ${ }^{1}$, Kyung-Sook Hong ${ }^{1}$, Ki Seok Choi ${ }^{1}$, Chan Young Ock', Hua Hong ${ }^{1}$, Young-Min Han ${ }^{1}$, Nam-Soo Paek², Sung-Soo Kim³, Ki Baik Hahm ${ }^{1}$

${ }^{1}$ Laboratory of Translational Medicine, Lee Gil Ya Cancer \& Diabetes Institute, Gachon University of Medicine and Science, Inchon, ${ }^{2}$ Mediogen Corp., Seoul, ${ }^{3}$ Research Division for Food Industry Promotion, Korea Food Research Institute, Seongnam, Korea

Introduction: Helicobacter pylori infection has been implicated in acute gastritis, chronic atrophic gastritis, peptic ulcers as well as gastric cancer. Since we have documented that anti-H. pylori, antiinflammatory, anti-oxidative, and anti-mutagenic actions of Korean red ginseng and the enhancing anti-inflammatory activities and attenuating anti-inflammatory roles of Lactobacillus plantarum, in the current study, we investigated the effects of L. plantarum-fermented Korean red ginseng on subacute or chronic pathology in H. pyloriinfected mouse model.

Methods: 5-week-old interleukin-10 deficient mice were inoculated with H. pylori (Sidney strain 1), after which L. plantarum (Lp), Korean red ginseng (RG) and fermented Korean red ginseng (FRG) were administrated by drinking water for 14 or 24 weeks. After killing, in addition to gross and pathologic evaluations, the expressions of inflammatory enzymes or cytokines were analyzed by Western blot analysis or ELISA, respectively.

Result: H. pylori infection induced the expression of inflammatory enzymes, iNOS and COX-2, and cytokines such as IL- $1 \beta$ and IL-6 in subacute 14 weeks model. Moreover, $H$. pylori infection significantly provoked tumorigenesis in chronic 24 weeks model. Lp, RG and FRG inhibited the expression of inflammatory enzymes and cytokines in both subacute and chronic models. Among those, FRG showed the significant anti-inflammatory and anti-tumorigenic effects on $H$. pylori-infected gastric carcinogenesis reflected with decreased incidence of tumor formations.

Conclusion: Probiotics fermented Korean red ginseng exerted significant protections against $H$. pylori infection through attenuating gastritis, rescuing from tumorigenesis and enhancing gastroprotection. We suppose that chronic intake of FRG can be an anticipating strategy in chemoprevention of $H$. pylori-associated gastric cancer.

\section{0-2-3}

\section{S-allylcysteine for Amelioration of GI Inflammation: Anti-Inflammation Based on HDAC Inhibition and Antioxidation}

Ki Seok Choi, Eun Hee Kim, Kyung Sook Hong, Huo Hong, Yoon Jae Kim, Jun Won Chung, Jung Ho Kim, YeongGeol Chung, Ki Baik Hahm ${ }^{1}$

Laboratory of Translational Medicine, Lee Gil Ya Cancer and Diabetes Institute and Department of gastroenterology, Gachon University of Medicine and Science, Inchon, Korea

Introduction: S-allylcysteine (SAC), one of the major garlic compounds, has been shown to have anti-inflammatory and antioxidative effects by numerous studies, which is one of garlic-derived organosulfur compounds. In the current study, we have investigated the pharmacological function of SAC at the gene levels using microarray and whether SAC has anti-inflammatory and anti-oxidative effects in LPS-treated RAW 264.7 cells.

Methods: We used mouse macrophage RAW 264.7 cells and inflammation was induced by LPS. SAC was pretreated $2 \mathrm{~h}$ before LPS treatment. MTT assay was employed to evaluate the cytotoxicity of SAC. To measure the antioxidative activity of SAC, we used electron spin resonance. To observe the anti-inflammatory effects of SAC, we performed RT-PCR, Western blot analysis, and Raybiotech array system. N-acetylcysteine (NAC), DATS, and TSA were used to compare as positive controls. In addition, we also investigated the effects of SAC on HDAC activity in LPS-treated RAW 264.7 cells. We also checked gene expression microarray compared to TSA.

Result: $H$ SAC showed very potent anti-oxidative activity comparing to NAC at $0.5 \mu \mathrm{M}$. Raybiotech array to evaluate anti-inflammatory effects of SAC showed that vascular cell adhesion molecule-1 (VCAM-1) expression was significantly decreased in SAC treated group compared to NAC, DATS, or TSA. In addition, SAC attenuated mRNA expression of proinflammatory genes and protein expression (iNOS and COX-2) in vitro. On the comparison to Sulforaphane, a well-known HDAC inhibitor, SAC was more effective in HDAC activity inhibition. In gene expression array showed that the treatment of SAC induced genes related to response to stress, immune response, signal transduction and cell proliferation. Especially, PKC theta involved in signal transduction and response to stress was increased 11-fold of control. Upregulated genes also include early growth response 1, prostaglandin-endoperoxide synthase 2, and heparin-binding EGF-like growth factor involved in cell proliferation. On the contrary, TNA superfamily including lymphotoxin beta and chemokine such as CXCL12, CXCL1, CXCL14, CCL20 were decreased after treatment of SAC. Gene expression of caspase-1, cyclin D2, and BMP-4 also are decreased.

Conclusion: Taken together, SAC is superior to NAC in protecting cells from oxidative or inflammatory stress under same condition. Therefore, SAC might be effective in preventing and/or attenuating the progress of these processes. 


\section{0-2-4 \\ Different Time Point of Probiotic Interferes Improve the Eradication Rate of Triple Therapy on Helicobacter pylori: A Multicenter Randomized Controlled Study in Shanghai}

Yiqi Du, Tun Su, Yanfang Gong, Zhaoshen Li

Department of Gastroenterology, Changhai Hospital, Second Military Medical University, China

Introduction: Long term infection of $H$. pylori is proved high risk factor of gastric cancer. Addition of probiotics can improve the eradication effect of triple therapy on $H$. pylori but the best time to interfere remains unclear. Here we want to determine whether adding the Lactobacillus acidophilus either before or after the traditional regimen could help to increase the $H$. pylori eradication rate.

Methods: This open randomized trial totally recruited $234 \mathrm{H}$. pylori positive gastritis patients from seven local centers. The patients were randomized into three groups: 79 patients (group OCA) took a one-week standard triple therapy (omeprazole, clarithromycin, amoxicillin), 78 (group POCA) and 77 patients (group OCAP) took a two-week probiotics before and after the triple therapy, respectively. Successful eradication was defined as a negative $\mathrm{C}^{13}$ or $\mathrm{C}^{14} \mathrm{UBT}$ four weeks after triple therapy. Data was analyzed both by intention-totreat (ITT) and per-protocol (PP) methods.

Result: Totally 171 patients received negative $H$. pylori results after the treatment $(\mathrm{n}=228, P P$ set $)$. According to $I T T$ analysis, the eradication rate in POCA and OCAP group is $79.5 \%(62 / 78,95 \% \mathrm{CI}$ $70.4 \sim 88.6)$ and $79.2 \%(61 / 77,95 \% \mathrm{CI} 70 \sim 88.4) . P P$ analysis showed $81.6 \%$ and $82.4 \%$ patients got $H$. pylori eradicated in POCA and OCAP groups. Comparing with the eradication rate of OCA $(60.8 \%$, ITT and $61.5 \%, P P)$, L acidophilus contained treatment shows a statistical superiority $(\mathrm{P}=0.007)$. No severe side effects could be observed in all trial groups.

Conclusion: The results suggest that either the pre- or postusage of probiotics may improve the $H$. pylori eradication effect of the standard triple therapy. The best time to interfere remains to be undetermined.

\section{0-2-5 \\ ERCP via PEG Hole}

Takao Endo1, Yasushi Adachi', Yoshiaki Arimura², Yasuhisa Shinomura ${ }^{2}$

${ }^{1}$ Department of Gastroenterology, Sapporo Shirakabadai Hospital, ${ }^{2}$ Department of Internal Medicine,

Sapporo Medical University, Japan

Percutaneous endoscopic gastrostomy (PEG) has been established as a safe and effective nutritional therapy technique for old-aged patients suffering from swallowing dysfunction. Although such bedridden patients tend to become cholecystolithiasis, conventional oral endoscopic (0E) therapy is difficult and becomes a risk of aspiration pneumonia because of their inability . Trans-gatorostomic endoscopy
(TGE) has several advantages over the OE. 1) Pharyngeal anesthetizing is unnecessary. 2) conversion of the patient's posture is unnecessary. 3) the distance between the orifice of endoscope insertion and the Vater papilla is very short. Concerning the removal of the common bile duct' stone, three endoscopic maneuvers via gastrostomic hole were compared.

\section{Oral Session 3 - Stomach \\ Chairpersons: Takashi Joh, Jose D. Sollano}

\section{0-3-1 \\ Seroconversion Rates of Helicobacter pylori Infection in Korean Adults}

Jihoon Jung, Kee Don Choi, Hwoon-Young Jung

Departments of Gastroenterology, Ulsan Collage of

Medicine, Asan Medical Center, Seoul, Korea

Introduction: As Helicobacter pylori infections during childhood are decreasing in Korea, we can expect that seroconversion is increasing during adulthood. However, there has only been one study regarding seroconversion and its reversion rate in the Korean population. This earlier, prospective study was confined to a male population. The purpose of this study was to evaluate the overall sero-prevalence, seroconversion rate, and the seroreversion rate of $H$. pylori infection.

Methods: We retrospectively selected healthy adults who had taken health screening at Asan Medical Center, Seoul, Korea more than twice, without any symptoms, between 2001 January and 2010 December. We reviewed the results of the anti-H.P Ab IgG, esophagogastroduodenoscopy, and the questionnaire. And statistical analysis was performed.

Results: A total of 67,212 people were enrolled in this study. The mean follow-up duration was 4.6 years, and the mean number of their screening examination was 3.91 times. The overall proportions of persistent sero-positive, persistent sero-negative, seroconversion, and seroreversion were $53.1 \%, 32.5 \%, 4.3 \%$, and $10.1 \%$, respectively. The overall seroconversion rate was 9.37 per thousand per year. The seroconverion rates of males and females were 10.63 and 7.34 per thousand per year, respectively. And the seroconversion rates of below the age of 40,40 to 55 , and over 55 were $6.73,8.49$, and 13.1 per thousand per year. To evaluate the risk factors for seroconversion, we compared the persistently sero-negative group and the seroconversion group. Univariate analysis showed that smoking $(\mathrm{p}<0.001$, OR: 1.75), severe alcoholism $(\mathrm{p}<0.001$, OR: 1.81$)$, and a history of gastric ulcers $(\mathrm{p}<0.017$, OR 1.22$)$ were risk factors of seroconversion. Diabetes, hypertension, a history of duodenal ulcers, regular exercise, socioeconomic status, and a history of abdominal pain showed no statistical difference.

Conclusion: Our study showed that the seroconversion rate of healthy adults in Korea is 9.37 per thousand per year and that the risk factors for seroconversion are male sex, patient age, smoking, severe alcoholism, and a history of gastric ulcers. 


\section{0-3-2 \\ An Optical Diagnosis for Gastric Cancer Using Fluorescence Observation}

Tsuyoshi Kaneko, Hirofumi Matsui, Osamu Shimokawa, Yumiko Nagano, Rai Kanho, Hideo Suzuki, Kuniaki Fukuda, Toshikazu Moriwaki, Kazunori Ishige, Toshiaki Narasaka, Masato Abei, Shinji Endo, Yuji Mizokami, Ichinosuke Hyodo

Department of Gastroenterology, University of Tsukuba, Japan

Introduction: We have previously reported that NSAIDsderived reactive oxygen species (ROS) increased cellular membrane fluidity: this phenomenon could be detected by an optical method, fluorescence polarization (FP). Many studies have shown that cancer cells have much higher concentration of ROS than normal cells. In this study, we cleared whether membrane fluidity of gastric cancer specimens increased or not. We also elucidated the feasibility of FP as an optical diagnostic tool. Moreover, we investigated the relation between ROS and FP in vitro.

Methods: A: Gastric cancer specimens from eleven patients were investigated. FP values of each sample were measured with a specially designed system composed with an intensified CCD, a fluorescence microscope and an image-processor. We compared each FP value of the specimens with the result of pathological examinations to evaluate the diagnostic accuracy of FP value analysis. B: We used gastric epithelial RGM1 cells and its cancerous transformed mutant RGK as normal and cancer model, respectively. We also established RGK' cells that overexpressed manganese superoxide dismutase protein, which scavenges mitochondrial ROS. We examined intracellular concentrations of ROS, membrane lipid peroxidation and FP value with fluorescent probes hydroxyphenyl fluorescein (HPF), diphenyl1-pyrenylphosphine (DPPP) and DAF, respectively.

Result: A: The sensitivity and specificity of FP analysis on human gastric cancer specimens was $84.3 \%$ and $70.4 \%$, respectively. B: Intracellular ROS concentration, amount of lipid peroxidation and membrane fluidity were significantly increased in cancerous RGK cells than those of normal RGM1 cells, but were significantly decreased in mitochondrial ROS-scavenged RGK' cells than those of RGK cells.

Conclusion: In cancer cells, higher ROS concentration is most likely to induce a smaller FP value. The FP analysis was demonstrated to be a clue to accurately diagnosing cancerous areas.

\section{0-3-3 \\ Effect of Eradication of Helicobacter pylori on Recurrence After Endoscopic Mucosal Resection of Gastric Adenoma and Early Gastric Cancer}

Suh Eun Bae, Hwoon-Yong Jung, Young Soo Park, Do Hoon Kim, Jin-Ho Kim, Ho June Song, Gin Hyug Lee, Kee Don Choi, Ji Young Choi, Mi-Young Kim, Jeong Hoon Lee, Kwi-Sook Choi, Ji Yong Ahn, Ji-Hoon Jung

Department of Internal Medicine, Asan Medical Center, University of Ulsan College of Medicine, Seoul, South Korea

Helicobacter pylori infection induces chronic inflammation in gastric mucosa and promotes the occurrence of gastric cancer. The effect of $H$. pylori treatment on recurrence after endoscopic mucosal resection of gastric cancer remain uncertain.

A total of 2089 adult patients aged between 28 and 88 years had undergone EMR of gastric adenoma and early gastric cancer from November, 2004 to December, 2008 were investigated retrospectively. Among them, the 601 patients had been excluded from the study because of short follow up duration $(<1$ year) and short recurrence interval ( $<3$ months) and no tests of urea breath test or rapid urease test or histology for diagnostic test of $H$. pylori. We investigated group without $H$. pylori infection $(\mathrm{n}=412.27 .6 \%)$, group with only positive $\operatorname{IgG}(\mathrm{n}=118,7.9 \%)$, group with $H$. pylori infection and successful eradication $(n=669,44.9 \%)$, group with $H$. pylori infection and failed eradication $(\mathrm{n}=28,1.8 \%)$ and group with $H$. pylori infection and no eradication $(\mathrm{n}=261,17.5 \%)$ for sex, age, smoking, alcohol, depth of tumor, histology type, atrophy, metaplasia, location of tumor, duration of follow up, recurrence rate, recurrence free survival.

Among total enrolled patients $(n=1488)$, male was $77 \%$, mean age was $62 \pm 9$ years old, mean duration of follow up was 49 months and mean recurrence interval was 21 months (median 16 months). There was no significant difference in recurrence rate in group with only positive IgG and group with successful eradication comparing group without $H$. pylori infection. There was significant difference in recurrence rate in group with failed eradication and group without eradication comparing group without $H$. pylori infection $(5.6 \%$ vs $25.0 \%$ vs $16.5 \%$, Hazard rate 1 vs 4.7 vs 3.2 in multivariate analysis)

A retrospective study showed that successful eradication of $H$. pylori may reduce the recurrence in the patients received EMR of adenoma and early gastric cancer. 


\section{0-3-4 \\ Dose Transnasal Endoscopy for Percutaneous Endoscopic Gastrostomy Decrease Local Infection?}

Tomoko Koide ${ }^{1}$, Masahiko Inamori ${ }^{2}$

${ }^{1}$ Gastroenterology Division, Yokohama City University Hospital, ${ }^{2}$ Office of Postgraduate Medical Education, Yokohama City University Hospital, Japan

Percutaneous endoscopic gastrostomy is the standard method for enteral feeding. Transnasal endoscopy for PEG is now available. The aim of this study was to assess transnasal endoscopy for PEG in our experienses. Between August 2005 and July 2009, 231 patients underwent PEG at our hospital. We analyzed the clinical characteristics of the patients related to transnasal endoscopy for PEG. The percutaneous endoscopic gastrostomy was performed using the transnasal endoscopy for PEG in 113 of these patients (49\%), whereas the transoral endoscopy for PEG was employed in the remaining 118 patients $(51 \%)$. In the multiple logistic regression analyses, the use/non-use of transnasal endoscopy was identified as a variable significantly associated with the incidence of local infection (odds ratio $0.230,95 \%$ confidence interval $0.074-0.72 ; \mathrm{P}=0.0116$ ). Use of transnasal endoscopy for performing PEG may be associated with the decreased incidence of the local infection.

\section{0-3-5}

\section{Rebamipide Effect on Chronic Gastritis in Dyspeptic Patient: Symptoms, Endoscopic an Histological Evaluation}

\section{Ari Fahrial Syam, Marcellus Simadibrata, Aziz Rani, Achmad Fauzi, Murdani Abdullah \\ Gastroenterology Division - Department of Internal Medicine - Faculty of Medicine, University of Indonesia, Jakarta, Indonesia}

Background/Aim: Rebamipide is a gastro-protective drug for gastritis patients and has been widely used as an anti-gastritis and anti-ulcer agent in patients with dyspepsia. Rebamipide also appears to be a suitable drug for the treatment of chronic gastritis patients whose symptoms and inflammation in gastric mucosa are not improved by acid-suppressive agents. The aim of this study was to evaluate the efficacy of rebamipide for the relief of dyspeptic symptoms and improvement in endoscopic and histological appearances in patients suffering from chronic gastritis in Indonesia.

Method: We selected forty five patients with moderate and severe gastritis endoscopically from 2009 to 2010 at Division of Gastroenterology, Department of Internal Medicine, University of Indonesia/Cipto Mangunkusumo hospital. All selected patient were given rebamipide $300 \mathrm{mg}$ /day for 28 days. Before and after rebamipide treatment the patient were performed endoscopical examination and were taken 5 biopsies for histological examination. Data were analyzed with $t$ test or wilcoxon signed rank test. The symptoms were recorded on day- 0 and day- 28 . The severity symptoms were measured by VAS.
Result: The most frequent characteristic was male (51.1\%), age 42.7311 .52 years old. The mucosal damage on day- 0 was $2.2680 .45 \mathrm{vs}$ day-28 was $1.7070 .78(P<0.001)$. There was a significantly improvement of epigastric pain score on day 28 and day 7 after rebamipide compared to day-0 $(P<0.05)$. The score of nausea, anorexia, bloating, belching and early satiety score on day 28 and day 7 after rebamipide was also improved significantly compared to day $0(P<0.05)$. The endoscopical severity score on day-28 was improved significantly compared to day- 0 . The degree of activity of chronic mononuclear inflammatory cells in both corpus and antrum was higher than polymorphonuclear neutrophil activity in the same area (corpus 1.390 .54 vs 0.120 .40 ; antrum 1.410 .59 vs 0.120 .46 ). There were no differences in mononuclear cell infiltration and neutrophil activity between corpus and antrum on day-0 and day-28 $(P>0.05)$. The density of $H$. pylori colonization in the corpus was lower than in the antrum, with no significant differences before and after treatment $(P>0.05)$. There were no significant changes in atrophy and intestinal metaplasia between corpus and antrum of the stomach $(P>0.05)$.

Conclusion: Rebamipide significantly reduced dyspeptics symptoms associated with chronic gastritis. The improvement in symptoms was associated with the decreased of endoscopic severity score but not the histological appearance.

Keyword: rebamipide, chronic gastritis, endoscopical severity, histological severity

\section{0-3-6 \\ Protective Effect of Rebamipide for Free Radicals in Patients with Chronic Gastritis}

\author{
Marcellus Simadibrata', Aziz Rani ${ }^{1}$, Ari Fahrial Syam¹, \\ Septelia Inawati Wanandi², Achmad Fauzi', \\ Murdani Abdullah ${ }^{1}$ \\ ${ }^{1}$ Gastroenterology Division - Department of Internal \\ Medicine - Faculty of Medicine, University of Indonesia, \\ Jakarta, Indonesia, ${ }^{2}$ Department of Biochemistry - Faculty \\ of Medicine, University of Indonesia, Jakarta, Indonesia
}

Background/Aim: Free radicals have a role in the development of chronic gastritis. The aim of this study to know the effect and efficacy of rebamipide on free radicals in chronic gastritis.

Method: Forty five patients in the division gastroenterology Cipto Mangunkusumo Hospital Jakarta 2009-2010 with moderate and severe gastritis endoscopically were included in this study. Before and after rebamipide treatment the patient were performed endoscopical examination and were taken 5 biopsies for free radicals; (Malondialdehyde (MDA) \& Carbonyl Compound) examination. All patients were given rebamipide $100 \mathrm{mg}$ three times a day for 28 days. Data were analyzed with $\mathrm{t}$ test or wilcoxon signed rank test.

Result: A total of 45 endoscopy-confirmed moderate and severe gastritis patients were enrolled in the study. The mean age was 42.73 11.52 years old. The mucosal damage on day- 0 was 2.2680 .45 vs day-28 was $1.7070 .78 \quad(P<0.001)$. The endoscopic evaluation showed that moderate and severe gastritis decrease after treatment from $34(75.6 \%)$ to $18(40 \%)$ and $11(24.4 \%)$ to $8(17.8 \%)$. The mean gastric mucosal malondialdehyde (MDA) was decreased significantly on day-28 rebamipide compared to day-0 (From 5.28 3.54 on day-0 to 
4.152 .71 on day-28 $(P=0.047)$. The mean of carbonyl compound on day-0 was 4.143 .01 and on day-28 was $5.122 .71(P=0.642)$.

Conclusion: In this study we found that Rebamipide was effective to treat chronic gastritis and also decrease the levels of MDA in gastric mucosa.

Keyword: rebamipide, chronic gastritis, histological severity, MDA, Carbonyl compound.

\section{Oral Session 4 - Intestine and Colon}

\author{
Chairpersons: Shin Fukudo, Udom Kachintorn
}

0-4-1

\section{The Influence of Bilateral Adrenalectomy on Indomethacin Induced Small Intestinal Lesions in Rats}

\author{
Melinda Gyenge, Naoko Abe, Rie Matsuoka, Yuki Nakase, \\ Kikuko Amagase, Koji Takeuchi \\ Division of Pathological Sciences, Department of \\ Pharmacology and Experimental Therapeutics, Kyoto \\ Pharmaceutical University, Yamashina, Kyoto, Japan
}

Introduction: Glucocorticoids act as the final step in the activation of the hypothalamus-pituitary-adrenal system. We recently found that urocortin I (Ucn I), a corticotropin-releasing factor (CRF) agonist, prevented indomethacin-induced small intestinal lesions mediated by CRF2 receptors. However, it remains unknown whether endogenous glucocorticoids are involved in modulating the mucosal integrity against these lesions. We examined the influence of adrenalectomy and mifepristone (glucocorticoid receptor antagonist) against NSAID-induced small intestinal damage in rats.

Methods: Male SD rats were given indomethacin $(3,10 \mathrm{mg} / \mathrm{kg})$ subcutaneously and killed $24 \mathrm{~h}$ later. Ucn I $(20 \mu \mathrm{g} / \mathrm{kg})$ was given intravenously $10 \mathrm{~min}$ before the administration of indomethacin. Astressin 2B (CRF2R antagonist: $60 \mu \mathrm{g} / \mathrm{kg}$ ) was given intravenously $10 \mathrm{~min}$ before Ucn I. Mifepristone $(10 \mathrm{mg} / \mathrm{kg})$ was given peroral twice $0.5 \mathrm{~h}$ before and $6 \mathrm{~h}$ after indomethacin. Bilateral adrenalectomy was performed a week before the experiment. Intestinal motility, mucus secretion, enterobacterial count and iNOS mRNA expressions were examined.

Result: Indomethacin, at $10 \mathrm{mg} / \mathrm{kg}$, caused multiple hemorrhagic lesions in the small intestine, accompanied by a decrease in mucus secretion and increases in intestinal motility, enterobacterial invasion and iNOS expression. The severity of these lesions was markedly aggravated by adrenalectomy or pretreatment with mifepristone, accompanied by further enhancement of intestinal motility, bacterial invasion as well as iNOS expression. Adrenalectomy markedly potentiated the ulcerogenic and motility responses caused by indomethacin, and severe lesions occurred even at $3 \mathrm{mg} / \mathrm{kg}$ of indomethacin, together with marked hepermotility. By contrast, Ucn I prevented these lesions as well as such functional alterations, in an astressin-2B inhibitable manner, but the degree of protection was not significantly mitigated by adrenalectomy or mifepristone.

Conclusion: These results suggest that (a) adrenalectomy worsens the intestinal ulcerogenic response to indomethacin, and the increased intestinal motility may be a key element in the mechanism for this aggravation, (b) endogenous glucocorticoids play a role in mucosal defense against indomethacin-induced small intestinal lesions.

\section{0-4-2 \\ Protective Effects of Various Immunonutrients Against Gut Ischemia/ Reperfusion Injury in Rats}

\section{Takashi Kohtani}

Department of Surgery, Uwajima Municipal Yoshida

Hospital, Japan

Objection: Rats were orally treated with various immunonutrients for 2 weeks in advance to examine the effects of these immunonutrients to gut $(\mathrm{I} / \mathrm{R})$ injuries and function of neutrophil in rats.

Methods: 8-week-old male Wistar rats were reared at the Ehime University Animal Center while being given special diet and drinking water from 14 days before the experiment. A rat model of post-gut (I/R) injuries was created (SMAO model) involving 45-minute ischemia and the rats were tested $624 \mathrm{hrs}$ after reperfusion. The rats were fed with special diets containing immunonutrients (Group A: arginine rich diet. Group B: arginine deficient diet. Group C: glutamine rich diet. Group D: glutamine eficient diet.) for 14 days. $624 \mathrm{hrs}$ after reperfusion serum cytokine levels were measured with an ELISA kit accompanied by measurement of $\mathrm{CD} 4 / \mathrm{CD} 8$ ratio and phagocytic function of neutrophil using flowcytometry. The small bowel removed $6 \mathrm{hrs}$ after reperfusion was examined pathologically.

Results: When the removed small bowel was examined pathologically intestinalmucosal injury was less frequent in Group $C$ than in Group A B and D. Intestinal mucosal injuries were less severe in the group fed with glutamine rich diet. In analysis of serum cytokine levels elevation of IL- 6 and TNF- $\alpha$ at 6 hrs after reperfusion was suppressed in Group A C although this difference was not significant. Phagocytic function of neutrophil at each of the baseline and $624 \mathrm{hrs}$ after reperfusion was about $20 \%$ higher in Group A than in B and D.

Conclusion: These results suggest that prior oral ingestion of arginine rich diet can stimulate phagocytic function of neutrophil and intestinal mucosal injury arising from post-gut (I/R) injuries. Intestinal mucosal injuries were less the group fed with glutamine rich diet by orally.

\section{0-4-3}

The Effect of Metastasis Inhibition Induced by Picropodophyllin in Colon Cancer

Xiaoying Feng

Department of Gastroenterology, The Second Affiliated

Hospital of Dalian Medical University, Dalian, China

Introduction: Although colorectal cancer can be successfully treated by conventional strategies such as chemo/radiotherapy and surgery, a substantial number of cases, in particular those with liver 
metastases, remain incurable. The IGF-1R and its ligands, have been suggested to play pivotal roles in proliferation, survival and migration of adenocarcinoma cells of the colon/rectum. Thus, interference with the cyclolignan picropodophyllin (PPP) as a potent and selective inhibitor of IGF-1R may represent a therapeutic option for this malignancy. MMP-7 is widely expressed in colon adenocarcinomas, and that seems to correlate with metastatic potential of colon cancer cells. The aims of this study were to investigate the mRNA expression of IGF-1R, IGF-1 and IGF-2 and MMP-7 in colorectal cancer tissues and to assess the effect of PPP on migration and expression of IGF-1R and MMPs in colon cancer cell lines.

Methods: Tissues from 48 colorectal cancer patients were analyzed by semi-quantitative RT-PCR for expression of IGF-1R, IGF-1, IGF-2 and MMP-7 mRNA. The effects of PPP on cell migration in colon carcinoma cell line HT-29, were assessed by the scratch assay way, and the expression of IGF-1R, MMP-2, -7 and -9 was analyzed by Western blotting.

Result: Compared with nontumor tissues, colorectal cancer tissues showed significant overexpression of IGF-1R $(\mathrm{p}<0.05)$ and IGF-2 mRNA $(p<0.01)$. There was also an evident overexpression of MMP-7, which was detected in all cancer tissues, but was undetectable in all nontumor tissues, and was significantly correlated with the depth of infiltration $(p<0.05)$ and lymph node metastasis $(p<0.01)$. In addition, the effects of PPP in HT-29 cell line exhibited marked downregulation of IGF-1R, MMP-7 and -9 , and as compared with control and IGF-1 treated cells, scratch closure was clearly reduced by PPP in a dose-dependent manner.

Conclusion: IGF-1R, IGF-2 and MMP-7 mRNA are overexpressed in colorectal cancer. PPP strongly downregulates expression of IGF-1R and MMP-7, and inhibits migration in colon cancer cell line. These findings suggest a rationale for implicating the therapeutic use of PPP in human colorectal carcinoma.

\section{0-4-4 \\ Role of Milk Fat Globule-Epidermal Growth Factor 8 in Development of Colitis-Associated Cancer}

\section{Ryusaku Kusunoki, Shunji Ishihara, Ansary Md. Mesbah Uddin, Yasumasa Tada, Akihiko Oka, Nobuhiko Fukuba, Ichiro Moriyama, Takafumi Yuki, Yuji Amano, \\ Yoshikazu Kinoshita \\ Department of Internal Medicine II, Shimane University Faculty of Medicine, Japan}

Introduction: Colitis-associated cancer (CAC) is a colorectal disease that arises in patients suffering from inflammatory bowel disease (IBD), in which the process of chronic inflammation is responsible for neoplastic transformation of intestinal epithelial cells. Milk fat globule epidermal growth factor-8 (MFG-E8) promotes phagocytic clearance of apoptotic cells to maintain normal tissue homeostasis and modulate immune responses. However, its functions in gastrointestinal inflammatory disorders are largely unknown. We evaluated the roles of MFGE8 in colonic inflammation and its relationship to CAC development.

Methods: Experimental colitis was induced in 7-week-old male wild-type (WT) and MFG-E8 knockout (KO) mice by administration of dextran sodium sulfate (DSS). The time course of MFG-E8 expres- sion in inflamed colons was determined in WT mice. Colitis activity parameters (body weight, colon length, histological score, proinflammatory cytokine profiles) were determined in inflamed colon tissues obtained from WT and $\mathrm{KO}$ mice. A mouse CAC model was induced by intraperitoneal injection of azoxymethane (AOM) and administration of 3 cycles of DSS. The number and size of colonic tumors in $\mathrm{KO}$ mice were evaluated, then compared to those in WT mice.

Result: The colonic expression of MFG-E8 was increased during the inflammatory and regenerating phases of DSS colitis. Although the severity of colonic inflammation in KO mice was significantly greater than that in WT mice, the number and size of colonic tumors in $\mathrm{KO}$ mice were relatively lower than those in WT mice.

Conclusion: MFG-E8 has protective and regenerating roles during colonic inflammation, though those functions may also contribute to tumorigenesis and tumor growth in CAC.

\section{0-4-5 \\ The Role of Miniprobe Sonography in the Severity Assessment and Prediction of Remission of Uncreative Colitis}

Hu Duanmin, Xia Lu, Zhu Oi

Department of Gastroenterology, Rui Jin Hospital, Shanghai Jiaotong University School of Medicine, Shanghai, China

Introduction: Ulcerative colitis (UC) is a chronic intractable inflammatory bowel disease with repeated flare-ups and remission. There are few and conflicting data on EUS features of the colonic wall of UC. The aim of our study was to determine whether Miniprobe sonography (MPS) could firstly assess the severity of UC, and secondly predict remission in UC.

Methods: During a 10-month period, 34 patients with UC participated in a prospective study. The determination of diagnosis and clinical severity of disease was followed by the colonoscopy and biopsy. All the subjects were treated by orally Balsalazide sodium at the dose of $6.75 \mathrm{~g} /$ day for eight weeks. Before and after treatment, the patients underwent the colonoscopy and MPS for evaluation of severity of UC. We evaluated the association of several parameters on MPS (total wall thickness, submucosal thickness, number of enlarged vessels in the submucosa and number of pathological lymph nodes around the rectum and sigmoid colon) with conventional endoscopic and histological findings. All the colonoscopic and histopathological results and parameters on MPS in the same patient were compared before and after treatment.

Result: After eight weeks of treatment, 20 patients underwent the second colonoscopy and MPS. Among them, marked improvement of the clinical symptoms appeared in $18 / 20$ patients $(90 \%)$ and histological remission of the colonic mucosa was achieved in 14/20 patients (70\%). Ultrasonographic findings in active stage showed significant thickening of the submucosa $(2.96+0.73 \mathrm{~mm})$ in comparison with the stage of emission $(2.12+0.35 \mathrm{~mm})(p<0.05)$, while no substantial alteration of the total colonic wall thickness was found between acute and quiescent UC $(3.84+0.64 \mathrm{~mm} / 3.62+0.61 \mathrm{~mm}$, respectively, $p=0.15$ ). In addition, a poorly demarcated wall structure from the first to the third layers was characteristic for acute UC, which returned normal in quiescent UC. In active stage of UC a number of paracolonic echopoor lymph nodes were present in $5 / 20$ patients 
(20\%), but still remained in the stage of emission. The pathologically enlarged vessels were not found in both acute and quiescent UC.

Conclusion: With MPS, Endosonographic measurements of submucosa thickness and observation of colonic wall layer structure provide clinically significant information in assessing the severity and predicting remission of UC.

\section{Oral Session 5 - Intestine and Colon}

Chairpersons: Fumiaki Ueno, Takayuki Matsumoto

\section{0-5-1 \\ Experimental Study on Syk Gene Transfection to Human Colon Cancer Cell Lines}

Yu Oing-Gong, Chang Hui-Li

Department of Gastroenterology, Zhongshan Hospital of Dalian University, China

Introduction: To construct the retrovirus vector carrying Syk gene, the effect of Syk gene transfection on the growth of humen colon cancer cell lines was observed.

Methods: The cDNA fragment part of the Syk gene was PCRamplified and insert into the retroviral vector pLNCX. The construct Syk expression vector was proved to be the same as designed by restriction endonuclease analysis and sequencing. Lovo cells were transfected with the recombinant retrovirus vector by using Lipofectamine reagent according to the manufacturer's instructions. By using Southern blot RT-PCR amplification, DNA sequencing, MTT, stable cell clones expressing Syk were detected and observed for the changes of their biologic characteristics.

Result: Exogenous Syk was successfully trsnsferred into LoVo cell and obtained stable expression. The Syk gene could significantly repress the proliferation of LoVo cells.

Conclusion: Effects of Syk gene on LoVo cell growth was caused by its expression of exogenous Syk mRNA.

\section{0-5-2}

Sonic Hedgehog as Pathogenic Contribution to Colitis-Associated Cancer and Prevention with Inhibitors of Shh

Yoon Jae Kim, Eun-Hee Kim, Kyung-Sook Hong, Ki Seok Choi, Hua Hong, Young-Min Han, Jong Joon Lee, Jung Ho Kim, Ki Baik Hahm ${ }^{1}$

Gachon University Gil Medical Center, Department of Gastroenterology, Incheon, Korea

Introduction: The activation of hedgehog $(\mathrm{Hh})$ signaling, which is critical to normal mammalian gastrointestinal development, is impli- cated in the development of various tumors, including brain tumor, lung cancer, pancreatic cancer, stomach cancer, and colorectal cancer. In the stomach, sonic hedgehog (Shh) was known to be decreased as the gastric lesion progressed to atrophic change, whereas its expression increased in gastric cancer after Helicobacter pylori, signifying that Shh contributed to gastric carcinogenesis. Since we have published the evidence that colitis-associated cancer can be controlled by anti-inflammatory intervention, we hypothesized that under the preliminary study that Shh contributed to colitic cancer development, Shh inhibitor might imposed cancer prevention in colitic cancer.

Methods: C57BL/6 mice were treated with AOM followed with $3 \%$ DSS administration to generate colitis-based carcinogenesis. The Western blot and immunohistochemical staining of Shh and related signaling molecules including PATC, Smo, Gli were performed. In vitro documentation using colon cancer cell lines were used to document the influence of Shh inhibition.

Result: Colitis promoted AOM-initiated colon carcinogenesis, linking the connection between inflammation and carcinogenesis in the colon. In a serial observation of Shh during colitic cancer development, Shh significantly contributed to carcinogenesis, among which anti-apoptotic mechanisms and subsequent privilege of proliferation were potentially contributed. Currently the administration of cyclopamine, cerulein, and itnaconazole, all reported to be inhibitors of Shh, was continued to check the cancer preventive outcomes in AOM initiated, DSS promoted-colitic cancer model.

Conclusion: As much as successful treatment of basal cell carcinoma with Shh inhibitor, potentiality of Shh inhibitor is anticipated in colitis-induced carcinogenesis through the plausible action of bioregulating inflammation based oncogenesis.

\section{0-5-3 \\ The Background of Colitis-Associated Cancer of UC Patients}

\author{
Kazuhiko Uchiyama, Yuji Naito, Tomohisa Takagi, \\ Akihito Harusato, Naohisa Yoshida, Kazuhiro Katada, \\ Kazuhiro Kamada, Takeshi Ishikawa, Osamu Handa, \\ Jun-ichi Sakagami, Hiroaki Yasuda, Hideyuki Konishi, \\ Nobuaki Yagi, Satoshi Kokura, Toshikazu Yoshikawa \\ Molecular Gastroenterology and Hepatology, Kyoto \\ Prefectural University of Medicine, Japan
}

Introduction: Ulcerative colitis (UC) is idiopathic inflammatory disorders of intestine extended proximally from the anal verge to involve all or part of the colon. It has been reported that recurrent inflammation with ulceration and tissue restitution confers an increased risk of colitis-associated cancer. As the prognosis of colitisassociated cancer is poor, special attention of surveillance should be paid for the patients of UC. In the present study, we investigated the background of the patients with colitis-associated cancer related to UC in our hospital.

Methods: All patients were attending the gastroenterology outpatient clinic at the Hospital of the Kyoto Prefectural University of Medicine. Diagnosis and classification of UC type were made according to clinical, radiologic, endoscopic, and histological criteria. 199 patients with UC were enrolled and investigated for the development of colitis-associated colorectal cancer. 
Result: A total of 8 patients were developed colitis-associated cancer during the median follow-up time 19.4 years. In contrast, the follow-up time of patients without cancer was 10.6 years. All the patients developed colorectal cancer were diagnosed as pan-colitis type, whereas the patients without cancer were diagnosed as $40.6 \%$ of pan-colitis type. The age of onset with UC (cancer/non cancer : 33.6/34.8 years) and distinction of sex (cancer F/M : 4/4, non cancer $\mathrm{F} / \mathrm{M}:$ 92/99) and the use of medication including 5-ASA, steroid, and immunomodulators showed no difference between the patients with and without colitis-associated cancer.

Conclusion: In our study, cumulative incidence rates of colitisassociated cancer over 10 and 20 years were $2.0 \%$ and $4.0 \%$ in all patients of UC. For pan-colitis type of UC, incidence rate over 10 and 20 years were $4.9 \%$ and $9.8 \%$. The special attention of surveillance should be paid for UC patients with pan-colitis type and over 10 years of follow-up time.

\section{0-5-4}

\section{A New Class of Non-Coding RNAs with Regulated Transcription and Disease- Specific Expression Profiles in Colorectal Cancer}

\author{
Sang Kil Lee1, Su Youn Nam ${ }^{1,2}$, Isidore Rigoutsos ${ }^{3}$, \\ George A. Calin² \\ ${ }^{1}$ Institute of Gastroenterology, Department of Internal \\ Medicine, Yonsei University College of Medicine, Seoul, \\ Korea, ${ }^{2}$ Department of Experimental Therapeutics and \\ Center for RNA interference and non-codingRNA, The \\ University of Texas M. D. Anderson Cancer Center, \\ Houston, TX, USA, ${ }^{3}$ Computational Medicine Center, and, \\ Department of Pathology, Anatomy and Cell Biology, \\ Thomas Jefferson University, Philadelphia, PA, USA
}

Introduction: It is widely accepted that the amount of non-codingRNAs (ncRNAs) exceeds by large the number of protein-coding genes. There is growing evidence that various types of ncRNAs are involved in the initiation, progression and dissemination of malignant cells. Here we report a new category of ncRNA transcripts that overlap short nucleotide patterns that have sequence complementarity with the untranslated and protein-coding regions of known genes.

Methods: The MDACC miRNA expression assay and protein coding gene expression by $44 \mathrm{~K}$ Agilent array were used. For determining the existence of ncRNA RACE, Northern blot was performed. To see the expression of ncRNA in various colorectal cancer cell (CRC) line, and CRC cancer qRT-PCR was used. After transfection of siRNA for ncRNA cell count analysis, apoptotic assay, invasion assay was done.

Result: NcRNA exhibit expression profiles that are specific to the tissue of origin. NcRNA exhibit differential expression in CRC versus normal samples and correlates with disease stage and with metastasis. Down-regulation of ncRNA by trasfection of siRNA induces cell death and accelerates apoptosis. Stable down-regulation of ncRNA expression reduce cancer invasion by the modulation of vimentin and E-cadherin.

Conclusion: Our present findings widely expand the spectrum of ncRNAs with multiple instances in the human genome that are abnor- mally expressed in cancers and uncover the potentially largest to date category of ncRNAs that can be widely used for translational purposes.

\section{0-5-5 \\ The Expression of Survivin in Colorectal Carcinogenesis and the Relations with Clinicopathologic Characteristics}

\author{
Lian-Jie Lin, Yu Jin, Ying Ma, Wei-Guo Jiang, Tie Ma, \\ Chang-Qing Zheng \\ Department of Gastroenterology, the Shengjing Hospital \\ of China Medical University, China
}

Introduction: Disturbance of apoptosis is thought to contribute to neoplastic transformation and progression. Survivin, a number of inhibitor of apoptosis family, directly inhibits caspase- 3 and -7 activity or caspase-9, and regulates the cell cycle in the G2/M phase by interact with spindle microtubules. To identify the role of survivin in colorectal carcinogenesis and the relationship between Survivin and clinicopathologic characteristics of colorectal carcinoma.

Methods: Immunohistochemical staining of survivin was performed by the streptavidin-peroxidase (SP) technique for the 188 paraffin sections which included 30 normal colorectal mucosas, 41 adenomas with low grade dysplasia, 30 adenomas with high grade dysplasia, and 87 colorectal carcinomas. And analysis the relation to clinicopathologic characteristics of colorectal carcinomas.

Result: No immunoreactivity of survivin was seen in normal mucosas. The positive rate of survivin increased in the transition from normal mucosas to adenomas with low grade dysplasia to high grade dysplasia/ carcinomas $(0.0 \%, 31.7 \%, 56.7 \%$ and $63.2 \%$ respectively). Positive rate was related to Dukes stage, but not to sex, age, size, site, histological differentiation grade, nor lymphoid node metastasis.

Conclusion: The expression of survivin is the essential event in the early stage of colorectal carcinogenesis and plays an important role in the transition sequence and it is related to clinicopathologic stage (Dukes stage) of colorectal carcinoma. Survivin could be a new diagnostic and therapeutic target in colorectal cancer. 


\section{Poster Sessions}

\section{Digestion}

\section{Poster Session 1}

Chairperson: Shin'ichi Takahashi

\section{P-1-1 \\ Protein Expressions of EGFR, K-ras, P53 and Ki-67 in Colorectal Cancer, Gastric Cancer and Esophageal Cancer}

\author{
Lina Liu, Yun He, Haichen Lv, Mei Li, Shen Lv \\ Gastroenterology Dept., First Affiliated Hospital of Dalian \\ Medical University, Dalian, China
}

Introduction: In recent years, with the development of molecular biology, targeted therapy which specificity and the less of side effect has become the new breakthrough in cancer treatment. The carcinogenesis is a complex process, which refers to the activation of oncogene, the inhibition of anti-oncogene, the disturbance in the regulation of proliferation and the signal transduction pathway out of control and so on. Genes of EGFR, K-ras, P53 and Ki-67 play an important role in the tumor's carcinogenesis. Immunohistochemistry be used to test the protein expressions of EGFR, K-ras, P53, Ki-67 in colorectal cancer, gastric cancer and esophageal cancer. By analyzing the protein expressions of EGFR, K-ras, P53, Ki-67 in colorectal cancer, gastric cancer and esophageal cancer and their relationship with clinicopathological parameters, this project aimed to investigate the role of these four genes in the three gastrointestinal cancer. By analyzing the differents of carcinogenesis of colorectal cancer, gastric cancer and esophageal cancer, this project intends to provide reference for the choice of gene therapy.

Methods: Surgically resected and pathologically confirmed 110 cases of colorectal cancer, 73 cases of gastric cancer and 21 cases of esophageal cancer were collected. All clinical data such as patiens' gender, age, tumor location, histological type and pathological stage were recorded. None of these patients received either radiocherapy or chemocherapy before the surgery. To detect the experession of EGFR, $\mathrm{K}$-ras, P53 and Ki-67 in colorectal cancer, gastric cancer and esophageal cancer. All the results were statistically analyzed with SPSS11.5 software package.

Results: 1 . The positive rate of EGFR protein expression in gastric cancer group was obviously higher than colorectal cancer group $(P<0.05)$; The positive rate of $\mathrm{K}$-ras protein expression in esophageal cancer group and gastic cancer group was obviously higher than colorectal cancer group $(P<0.05)$; The positive rate of P53 protein expressions had no significant difference among the colorectal cancer, gastric cancer and esophageal cancer $(P<0.05)$; The positive rate of Ki-67 protein expression in gastric cancer group was obviously higher than colorectal cancer group and esophageal cancer group $(P<0.05)$.
2. In colorectal cancer, the positive rate of P53 protein expression in not reached the serosal layer group was lower than penetrated subserous layer group $(P<0.05)$; The positive rate of $\mathrm{Ki}-67$ protein expression in not reached the serosal layer group was lower than penetrated subserous layer group $(P<0.05)$.

In gastric cancer, the positive rate of EGFR protein expression in well-moderate differentiation group was lower than poor differentiation group $(P<0.05)$; The positive rate of $\mathrm{K}$-ras protein expression in not reached the serosal layer group was lower than penetrated subserous layer group $(P<0.05)$; and it in without lymph node metastasis group was lower than with lymph node metastasis group $(P<0.05)$; The positive rate of $\mathrm{P} 53$ protein expression in well-moderate differentiation group was lower than poor differentiation group $(P<0.05)$.

In esophageal cancer, the positive expressions rate of EGFR, K-rsa, P53 and Ki-67 have no obvious relationship with patiens' gender, age, tumour location, differention degree, depth of invasion and lymph node metastasis $(P<0.05)$.

3 . In colorectal cancer, $\mathrm{P} 53$ protein expression was positively correlated with $\mathrm{Ki}-67$ protein expression $(\mathrm{r}=0.86, P<0.05)$.

4. All patients were divided into 16 groups according to the protein expressions of the EGFR, K-ras, P53 and Ki-67 in colorectal cancer, gastric cancer and esophageal cancer. We found that the protein expression spectrums of EGFR, K-ras, P53 and Ki-67 in these three carcinomas are various.

Conclusions: 1. The EGFR, K-ras, P53 and Ki-67 protein all have expressions more or less in colorectal cancer, gastric cancer and esophageal cancer group.

2. EGFR and Ki-67 protein expressions in gastric cancer were highest, which indicates that maybe they are more close in carcinogenesis of gastric cancer; K-ras protein expression in esophageal cancer are highest, which indicates that maybe they are more close in carcinogenesis of esophageal cancer; P53 protein expression in colorectal cancer, gastric cancer and esophageal cancer have no significant difference, suggest that P53 play an important role in all digestive carcinoma.

3. In gastric cancer, the protein expressions of EGFR, P53 have negative correlation to cell differentiation, and the protein expression of K-ras has positive correlation to depth of invasion and lymph node metastasis; In colorectal cancer, the protein expressions of P53 and Ki-67 have positive correlation to depth of invasion.

4. P53 and Ki-67 protein expressions have a close relationship in colorectal cancer. It suggests that they may cooperate with each other in carcinogenesis.

5. The protein expression spectrums of EGFR, K-ras, P53 and $\mathrm{Ki}-67$ in these three carcinomas are various. It indicates that carcinomas located in different parts of digestive tract may have the same carcinogenesis, and the same carcinoma may have the different carcinogenesis.

\section{KARGER \\ (C) 2012 S. Karger AG, Basel}

Fax +4161306 1234

E-Mail karger@karger.ch

www.karger.com
Accessible online at: www.karger.com/dig 


\section{P-1-2 \\ A Retrospective Study for Incidence and Clinical Outcomes of Hospital-Acquired Pneumonia after Endoscopic Submucosal Dissection}

Chan Hyuk Park, Su Jin Heo, Suji Shin, Hyuk Lee, Jun Chul Park, Sung Kwan Shin, Yong Chan Lee, Sang Kil Lee

Department of Internal Medicine, Institute of Gastroenterology, Yonsei University College of Medicine, Seoul, Korea

Introduction: Hospital-acquired pneumonia after endoscopic submucosal dissection (ESD) is not uncommon, but little is known about its characteristics. We aimed to analyze the clinical features of pneumonia after ESD and to suggest the treatment plan.

Methods: Consecutive patients received ESD from January 2008 to June 2011 at Severance Hospital, Seoul, Korea were included. We retrospectively reviewed the patients' demographics, tumor characteristics, sedatives and medications.

Result: A total of 1878 patients with 2162 lesions who were underwent ESD were identified. Among 58 patients who showed abnormal chest radiography (CXR) and symptom of pneumonia, 19 patients $(1.01 \%)$ got pneumonia based on the definition of Centers for Disease Control (CDC), 20 patients (1.06\%) were suspected pneumonia but failed to satisfy CDC criteria and 19 patients (1.01\%) had only consolidation on CXR. The patients developed pneumonia were significantly older than those without pneumonia. (70.7 years vs. 64.5 years; $p=0.005)$. Male were more frequent in the patients with pneumonia than without pneumonia $(89.5 \%$ vs. $67.5 \%$; $p=0.047)$. Pneumonia seemed to be more common in the patients administrated propofol with or without midazolam than those administrated midazolam only ( 17 cases vs. 2 cases; $p=0.114$ ). Nine patients $(47.4 \%)$ of 19 patients who had only consolidation on CXR were treated with empirical intravenous antibiotics. Length of hospital stay and prognosis of the patients treated with intravenous antibiotics were not different from those of the patients not treated. All patients demonstrated consolidation without fever or respiratory symptom discharged without any medical problem.

Conclusion: Pneumonia after ESD was more frequent in old aged men. Propofol deep sedation during ESD showed a tendency to increase the incidence of pneumonia. It might be unnecessary to treatment with antibiotics in the patient demonstrated consolidation without fever or respiratory symptom.

\section{P-1-3 \\ The Role of Serum Pepsinogen in the Diagnosis of Gastric Diseases}

Zhang Xiao-mei, Li Xin-hua, Wang Juan, Zhang Gui-ying

Department of Gastroenterology, Xiangya Hospital, Central South University, Changsha, China

Introduction: serum pepsinogen (PG) levels are affected by many factors such as area, race, age, drinking habits and Helicobacter pylori infection status, et al. The serum PG concentrations in patients with different gastric diseases who were Chinese Han people of Hunan Province need to be surveyed and evaluated in order to investigate the essential characteristics of serum PG levels in this district, which is expected to provide a valuable reference for the surveys of gastric cancer.

Methods: 248 patients were selected in this study. All subjects were assigned to the following seven groups according to the gastroscopy and histologic assessment including 53 cases of non-atrophic gastritis, 20 cases of chronic atrophic gastritis, 36 cases of gastric ulcer, 31 cases of duodenal ulcer, 69 cases of advanced gastric cancer, 13 cases of early gastric cancer and 24 cases with partial gastrectomy for gastric cancer, one of them with recurrence of gastric cancer. In addition, 34 healthy volunteers were recruited as control from those undergoing endoscopic examination. Serum PG concentrations were determined by Enzyme-linked immunosorbent assay. PG I/II ratio was calculated. The data analysis used the SPSS 17.0 program. The ROC curve was used to find the cut off point for predicting gastric cancer with the best sensitivity and specificity.

Result: The serum PGI concentrations and PGI/PGII ratio were significantly lower in early and advanced gastric cancer group than in healthy controls $(\mathrm{P}<0.005)$. In contrast, the PGI concentrations in gastric ulcer group and the serum PG I and II level as well as the PG $\mathrm{I} / \mathrm{II}$ ratio in duodenal ulcer group were significantly higher than those in healthy controls $(\mathrm{P}<0.05)$. The serum PGI concentrations and the $\mathrm{PGI} / \mathrm{II}$ ratio in advanced gastric cancer group as well as the PGI/II ratio in early gastric cancer were lower than those in the atrophic gastritis group $(\mathrm{P}<0.001)$. The optimal cut-off levels for predicting gastric cancer were $70 \mu \mathrm{g} / \mathrm{L}$ for PGI (sensitivity, $82.1 \%$; specificity, $72.5 \%$ ) and 6 for PGI/II ratio (sensitivity, $82.9 \%$; specificity, $72.8 \%$ ). The areas under the PGI and PGI/II-ratio curves were 0.880 and 0.876 , respectively. when the concentration of serum $\mathrm{PGI} \leq 70 \mathrm{ug} / \mathrm{L}$ combined with $\mathrm{PGI} / \mathrm{PGII} \leq 6$, the diagnostic sensitivity and specificity of gastric cancer were $62.1 \%$ and $94.2 \%$ respectively. The combination of these two markers showed moderate sensitivity and higher specificity than used alone for GC screening.

Conclusion: Levels of serum pepsinogen subtypes are closely correlated with gastric diseases. Decreasing of PGI concentrations and PGI/PGII ratio levels is a risk factor for gastric cancer, which can be used as a serologic marker to screen and to help diagnosing gastric cancer. Combined with the serum PG I and the PGI/II ratio are valuable for the early diagnosis of gastric cancer.

\section{P-1-4 \\ Characteristics of Recurrent Early Gastric Cancer After Endoscopic Resection of Early Gastric Cancer}

\author{
Takatsugu Yamamoto, Koichiro Abe, Hajime Anjiki, \\ Taro Ishii, Yasushi Kuyama
}

Department of Internal Medicine, Teikyo University School of Medicine, Japan

Introduction: Endoscopic mucosal resection is widely performed as radical treatment for early gastric cancer. However, it is important clinical problem that cancer develops at high rate on the other site in same patients subsequently. Eradication therapy for 
Helicobacter pylori is reported as effective for suppressing the development of cancer, but the effect seems limited.

Methods: Here we conducted this clinical review of the patients underwent endoscopic mucosal resection to clarify the characteristics of development of new gastric cancer after the treatment. From 2002 till 2009, 98 patients underwent endoscopic mucosal resection against early gastric carcinoma at Teikyo University hospital (Tokyo, japan). The medical records were retrospectively reviewed.

Result: Three patients were diagnosed as having recurrent gastric cancer. All the patients had completed eradication therapy and negative for Helicobacter pylori at the recurrence. They were received periodical endoscopic examination after the endoscopic procedure more than one year, and the second lesions were diagnosed at the early stage. The pathological examination revealed that the newly developed lesions were well-differentiated adenocarcinoma.

Conclusion: We concluded that periodical endoscopic followup is important for improving the prognosis of newly developed gastric cancer as well as eradication therapy of Helicobacter pylori.

\section{P-1-5}

\section{Serum Pepsinogen Test and Dyspepsia Management: An Investigation on Diagnostic Accuracy in Clinical Setting}

\section{Hong Ouyang \\ Department of Endoscopy, The People's Hospital of Lin'an City, Hangzhou, China}

Introduction: Although there is plenty of research on dyspepsia diagnosis and management, the wildly accepted $H$. plyori test based and medication based strategy may still raise concern in high infection and high caner prevalence area. In area like China, the concern about gastric cancer caused us adopted a strategy that apply endoscopy on almost all dyspeptic patient. This brings so many endoscopic workloads that actually hindered careful mucosa inspection, and maybe the cause of low early cancer detection rat. A method to identify or filter patient with acute gastropathy is needed. The gastric mucosa biomarkers has been proved be useful for non-dyspeptic healthy subject in cancer screening, but the value on dyspeptic is unknown. In this study we explore the feasibility to use serum pepsinogen as screening tool for dyspeptic patient before upper GI endoscopy.

Methods: Dyspeptic patients came for upper endoscopy in continues time period is accessed for serum pepsinogens and clinical data. Endoscopy findings, mucosa histology and serum pepsinogen levels is analyzed.

Result: 214 patients included, mean age $46.97 \pm 13.33$ yod, 200 cases obtained biopsy form both part of stomach. Patients with abnormal endoscopy findings have high PG II serum level. To predict endoscopy abnormality with serum PG II, the sensitivity is $77.42 \%$, specificity $45.76 \%$, LR +1.43 , LR- 0.49 , for all patients. As for patients with positive PPI history before endoscopy, sensitivity is $60 \%$, specificity $80 \%$, LR +3 , LR- 0.5 . To predict mucosa abnormality with serum PG II for patients with PPI history, sensitivity is $75 \%$, specificity $72 \%$, LR+ 2.68, LR- 0.35 .

Conclusion: Serum PG II has mild specificity and sensitivity predicting endoscopy abnormality in dyspeptic patients. A perspective control trail should be considered to demonstrate the effectiveness.

\section{P-1-6 \\ Effects of Celecoxib on Cell Apoptosis in Human Gastric Cancer Cell Line BGC-823 and Expressions of Fas, FasL and Bcl-2}

\author{
Li Qian, Peng Jie, Li Xin-hua, Liu Ting, Yuan Wei-jian, \\ Zhang Gui-ying
}

Department of Gastroenterology, Xiangya Hospital, Central South University, Changsha, P.R. China

Objectives: To explore the effect of Celecoxib on cell apoptosis of human gastric cancer cell line BGC-823 and expression of Fas, FasL and Bcl-2.

Methods: Flow cytometry was used to quantify the influence of Celecoxib on the apoptosis of gastric cancer cell line BGC-823. The expressions of Fas, FasL, bcl-2 proteins were observed by Western blot analysis.

Results: 1. Flow cytometry found that the ratio of apoptotic cells increased with the concentration of celecoxib increased; Celecoxib concentration at $0,20,40,60,80,100 \mu \mathrm{mol} / \mathrm{L}$, ratio of apoptotic cells (\%) were : $0.503 \pm 0.018,5.870 \pm 0.325,11.396 \pm 0.267,17.567 \pm 0.376$, $24.439 \pm 0.326,52.933 \pm 2.575$. The apoptotic rates of cells between various concentration celecoxib groups has significant differences, $(\mathrm{P}<0.05)$. 2. Western blotting analysis showed: Celecoxib concentration at $0,20,40,60,80,100 \mu \mathrm{mol} / \mathrm{L}$, cultivating for $48 \mathrm{~h}$ on BGC-823 gastric cancer cells, Relative content of Fas protein were $0.1113 \pm 0.0037$, $0.1017 \pm 0.0065, \quad 0.1975 \pm 0.0100, \quad 0.3297 \pm 0.0053, \quad 0.4595 \pm 0.0045$, $0.5204 \pm 0.0148$; Relative content of FasL protein were $0.8070 \pm 0.0268$, $0.7311 \pm 0.0780, \quad 0.6254 \pm 0.0501, \quad 0.5465 \pm 0.0180, \quad 0.4378 \pm 0.0081$, $0.3760 \pm 0.0034$; Relative content of Bcl-2 protein were $0.5448 \pm 0.0049$, $0.5213 \pm 0.0326,0.4256 \pm 0.0421,0.3934 \pm 0.0305,0.2659 \pm 0.0121$, $0.2294 \pm 0.0081$. The expression of Fas was up-regulated, whereas the expressions of FasL and bcl-2 proteins were down-regulated in a concentration-dependent manner from 0 to $100 \mu \mathrm{mol} / \mathrm{L}$ in gastric cancer cell line BGC-823. The expressions of Fas, FasL and Bcl-2 proteins between various concentration celecoxib groups have significant differences ( $\mathrm{P}<0.05$, respectively). (Fig 1, 2, 3, respectively)

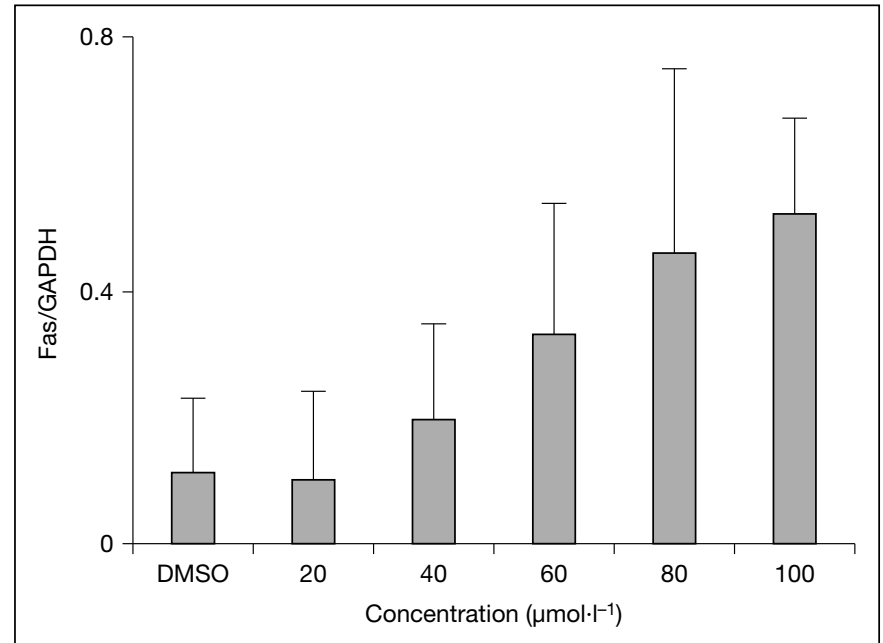

Fig. 1. Fas/GAPDH ratio histogram of different concentrations of celecoxib deal with gastric cancer cells BGC-823 for $48 \mathrm{hrs}$. The ratios increased in parallel to the increase of Celecoxib dose. 


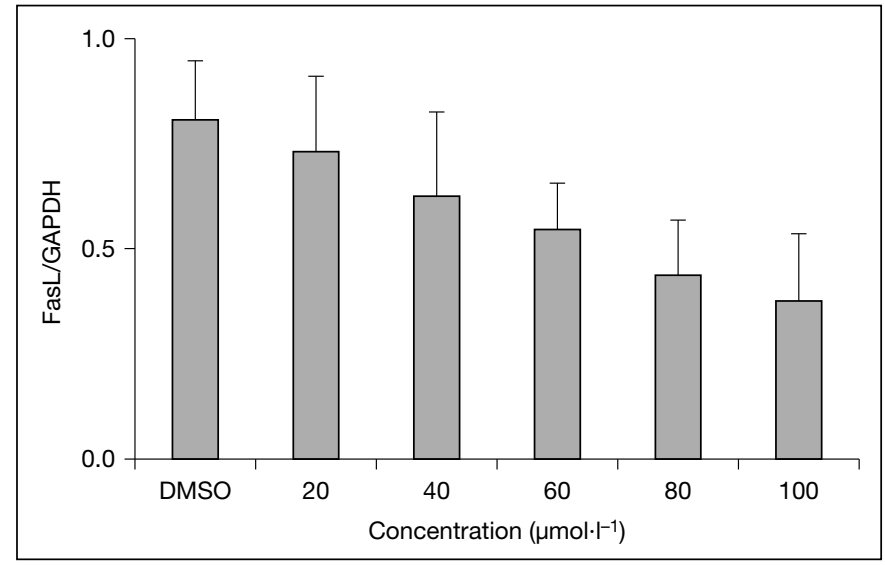

Fig. 2. FasL/GAPDH ratio histogram of different concentrations of celecoxib deal with gastric cancer cells BGC-823 for $48 \mathrm{hrs}$. The ratios decreased in parallel to the increase of Celecoxib dose.

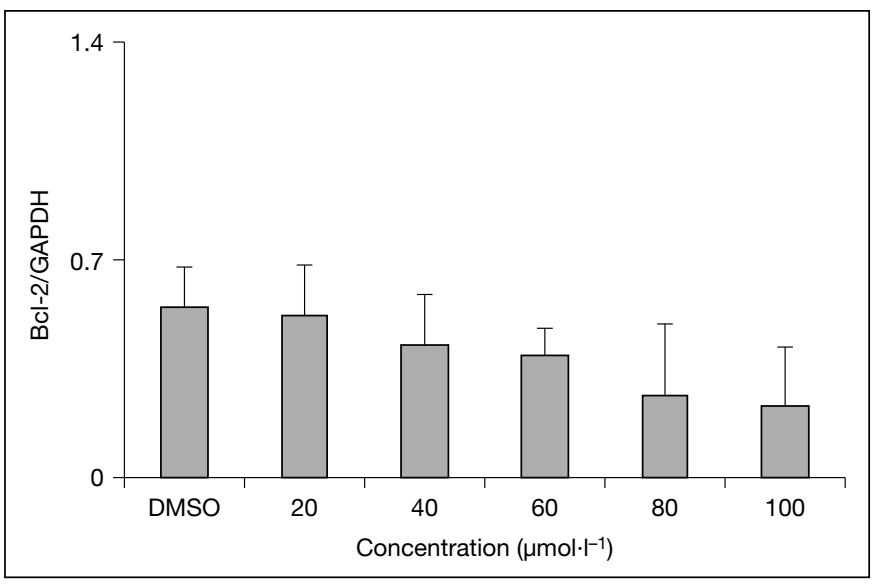

Fig. 3. Bcl-2/GAPDH ratio histogram of different concentrations of celecoxib deal with gastric cancer cells BGC-823 for $48 \mathrm{hrs}$. The ratios decreased in parallel to the increase of Celecoxib dose.

Conclusions: 1 Celecoxib-induced gastric cancer BGC- 823 cell apoptosis, to a certain range of dose-dependent manner. 2. At a certain celecoxib concentration scope, Fas protein increased and FasL, Bcl-2 protein reduced were dose-dependent manner. 3. Celecoxib induced cell apoptosis in gastric cancer cell line BGC-823, which may be associated with up-regulation of the expressions of Fas protein and down-regulated of the expressions of FasL and bcl-2 protein.

\section{Poster Session 2}

Chairperson: Ken Haruma

P-2-1

ING1 Plays an Important Role in Regulating AGS Cell Apoptosis by Down-Regulated Caspase 2 Gene Expression

XiangMin He

Department of Gastroenterology, The First Affiliated Hospital, China Medical University, China

Introduction: This study was to assess the mechanism of ING1 gene silencing on cell apoptosis of gastric cancer cell line AGS.

Methods: The synthetic siRNA specific to ING1 was transfected into AGS cells. Cell apoptosis was evaluated by flow cytometry and expression levels of ING1, caspase 2 and caspase 3 were detected by real-time PCR.

Result: The synthetic siRNA could effectively inhibit the expression of ING1 in AGS cells. The apoptosis cells number of ING1 knocked-down group was $6.70 \pm 0.41 \%$, which was significantly decreased compared with the control group $(11.06 \pm 0.97 \%$, $\mathrm{P}<0$. 05). 40 hours after transfection, the expression of ING1, caspase 2 and caspase 3 was $0.1707 \pm 0.06,0.125 \pm 0.03$ and $0.999 \pm 0.10$, respectively.

Conclusion: ING1 gene silencing could down-regulated caspase 2 gene expression and ING1 plays an important role in regulating AGS cell apoptosis by down-regulated caspase 2 gene expression.

\section{P-2-2 \\ Comparison of ESD Performance Under Intermittent Midazolam Injection and Propofol Continuous Infusion: Retrospective Study}

Jae Hun Min, Chan Hyuk Park, Su Jin Heo, Suji Shin, Hyuk Lee, Jun Chul Park, Sung Kwan Shin, Yong Chan Lee, Sang Kil Lee

Institute of Gastroenterology, Department of Internal Medicine, Yonsei University College of Medicine, Seoul, Korea

Introduction: Valid sedation method is essential to endoscopic submucosal dissection (ESD), however, there were very few reports about the effect of sedation methods on ESD performance and complication during the ESD.

Methods: From Jan 2008 until September 2010, intermittent midazolam injection was used during ESD for total of 1043 patients (Group A), and afterward, the propofol infusion was used to 456 patients by anesthesiologist (Group B) until May 2011 in Yonsei University Severance hospital Seoul Korea. We analyzed ESD performance and complication between two groups. We reviewed clini- 
copathologic factor of patients and lesion and clinical factors which could affect performance of ESD. ESD performances were determined by rate of en bloc resection, complete resection, complication (bleeding, perforation, and post ESD pneumonia) and ESD duration.

Result: The en bloc resection rate was significantly higher in the Group B than Group A $(\mathrm{P}<0.01)$. Duration of procedure was significantly shorter in the Group B than Group A $(\mathrm{P}<0.01)$. Incidence of perforation during ESD was higher in Group A $(p=0.03)$, but incidence of post ESD pneumonia was significantly higher in Group B $(\mathrm{p}<0.01)$. Complete resection rate and bleeding risk had no differences between two groups.

Conclusion: Continuous propofol infusion controlled by anesthesiologist for ESD seems more reasonable in terms of ESD performance and complication except post ESD pneumonia.

\section{P-2-3}

\section{Natural Course of Non-Curative Endoscopically Resected Differentiated Early Gastric Cancer}

\author{
Ji Yong Ahn', Hwoon-Yong Jung ${ }^{1}$, Ji Young Choi', \\ Mi-Young Kim ${ }^{1}$, Jeong Hoon Lee ${ }^{1}$, Kwi-Sook Choi', Do \\ Hoon Kim ${ }^{1}$, Kee Don Choi ${ }^{1}$, Ho June Song ${ }^{1}$, Gin Hyug \\ Lee ${ }^{1}$, Jin-Ho Kim¹, Young Soo Park ${ }^{2}$ \\ Departments of Gastroenterology ${ }^{1}$ and Pathology², \\ University of Ulsan College of Medicine, Asan Medical \\ Center, Asan Digestive Disease Research Institute, Seoul, \\ Korea
}

Introduction: In clinical practice after endoscopic non-curative resection of early gastric cancer (EGC), when the underlying disease is severe, the age is too old, or the patient deny further treatment, we should observe the patient with closed monitoring.

Methods: We analyzed the clinical characteristics and outcomes of 159 patients with differentiated EGC who underwent non-curative resection without additional treatment over 12 months. Of these, 90 patients (56.6\%) had underlying diseases, 77 (48.4\%) had lymphovascular invasion and/or margin involvement after endoscopic resection, and 127 (79.0\%) had submucosal invasion.

Result: Median survival of the 159 patients was 42 months (interquartile range [IQR], 30-66 months). Forty patients $(25.2 \%)$ died, 3 of stomach cancer, 34 from other causes, and 3 from unknown causes; their median survival after endoscopic treatment was 27.5 months (IQR, 13.8-48.3 months). Multivariate analysis showed that the rates of underlying disease $(p<0.001)$ and lymphovascular invasion $(p=0.005)$ were higher in the 40 patients who died than in the 119 survivors. The overall 3 - and 5-year survival rates were $82.9 \%$ and $77.1 \%$, respectively; the rates in patients with lymphovascular invasion were $61.9 \%$ and $42.4 \%$, and those in patients without lymphovascular invasion were $86.1 \%$ and $81.8 \%$, respectively $(p<0.001)$.

Conclusion: Additional surgery is strongly recommended in patients with EGC and lymphovascular invasion due to their high mortality rate.

\section{P-2-4 \\ Survivin, Caspase-3 Protein Expression in Gastric Cancer Tissue}

Xiuying Xu, Haichao Piao

Department of Gastroenterology, The First Affiliated

Hospital, China Medical University, China

Introduction: It has been found that the occurrence and development of stomach cancer is closely related to stomach cancer apoptosis. At present, the research on the stomach cancer cell apoptosis and its mechanism of regulation has become a hot topic. To study the expression of Survivin and Caspase- 3 and to discuss the role of them in stomach cancer occurrence and development and the correlation of the expression of both .

Methods: detected the expression of Survivin and Caspase- 3 in 42 cases of stomach cancer and adjacent normal tissue of 15 cases using immunohistochemistry.

Result: the expression of Survivin protein and Caspase- 3 protein in gastric cancer tissue is significantly different from in normal tissue $(\mathrm{P}<0.01)$. Survivin protein is highly expressed in gastric cancer tissue and Caspase- 3 is highly expressed in the adjacent tissue. The expression of Survivin and of caspase- 3 in stomach cancer was negatively relevant. he abnormal expression of Caspase-3, Survivin protein in gastric cancer significantly correlat with malignant biological behavior .

Conclusion: Over-expression of Survivin protein and Caspase-3 expression loss may play an important role in the development of stomach cancer.

\section{P-2-5 \\ Characteristics of Endoscopic Finding in Gastric Adenoma with High Grade Dysplasia Suggesting Gastric Cancer}

Jung Ho Kim, Yoon Jae Kim, Jong Joon Lee, Jun Won Chung, Kwang An Kwon, Dong Kyun Park, Ki Baik Hahm

Departments of Gastroenterology, Gachon University Gil Medical Center, Incheon, Korea

Introduction: Endoscopic submucosal dissection (ESD) was widely used for primary treatment for early gastric cancer. However forceps biopsies prior to ESD may be inadequate for accurate diagnosis of gastric neoplasm. The aim of this study was to elucidate the predicting factor for gastric cancer in patients with gastric adenomas with high grade dysplasia (HGD) at initial endoscopic diagnosis.

Methods: The medical record of patients who were pathologically confirmed gastric adenomas with HGD at initial diagnostic endoscopy between february 2008 and september 2010 were retrospectively reviewed. In 360 patients who were treated with ESD, 62 patients were included. The endoscopic findings were reviewed for gross type, surface color, surface nodularity, size and ulceration by two endoscopists.

Result: The mean age of the patients was 66.58 years old (range, 40-81 years). Forty-four patients were men. Seventeen patients were diagnosed as gastric cancer and 45 patients were diagnosed as ade- 
noma after ESD. The diameter of the lesions was $16.9 \mathrm{~mm}$ (range, 5-51 mm). Depressed type, mucosal ulceration and size were significant variables for predicting carcinomas. In the multivariate analysis, more than $3 \mathrm{~cm}(p=0.027)$ and mucosal ulceration $(p=0.017)$ were significant predicting factors suggesting early gastric cancer.

Conclusion: Our result suggested that, in patient with HGD at initial forceps biopsies, adenoma with mucosal ulceration or more than $3 \mathrm{~cm}$ should be considered a candidate for more endoscopic extended dissection to obtain safety resection margin.

\section{P-2-6 \\ Coexistence of Ulcerative Colitis and Iron Deficiency Anemia with Hepatitis C Virus- Related Cryoglobulinemia: A Case Report and Literature Review}

Yu-hong Huang, Min Jiang, Ming-jun Sun

Department of Gastroenterology, The First Affiliated

Hospital, China Medical University, Shenyang, China

Introduction: Cryoglobulinaemia is an immune complexmediated systemic vasculitis involving mostly small, but sometimes larger vessels, and can be associated with a variety of clinical conditions, including fatigue, vasculitis, purpura, arthralgias, and glomerulonephritis.

Ulcerative colitis is a common, chronic idiopathic inflammatory bowel disease. Patients typically present with bloody diarrhea and abdominal cramping. The presence of cryoglobulinemia in ulcerative colitis patients is unique.

Iron deficiency anemia is a common hematologic complication of inflammatory bowel disease. Aplasia anemia and anhemolytic anemia in cryoglobulinemia is less reported. Up to date, there is no Iron deficiency anemia is reported in cryoglobulinemia.

Methods: We report the first case of coexistence of ulcerative colitis and iron deficiency anemia with hepatitis $\mathrm{C}$ virus-related cryoglobulinemia, and review the literature.

Result: A diagnosis of HCV-related cryoglobulinemia with ulcerative colitis, iron deficiency anemia, and glomerulonephritis was made. The patient was treated with an initial dose of $60 \mathrm{mg}$ prednisone and oral iron supplementation. She responded well. Diarrhea ceased. The abdominal pain and the edema reduced. Routine studies on stool and renal function returned to normal. Routine studies on blood and urine, and serum albumin became better than just admission.

Conclusion: We reported the first case of coexistence of ulcerative colitis and iron deficiency anemia with HCV-related cryoglobulinemia in a female Chinese-ethnic patient. Our case report highlights the interesting association between $\mathrm{HCV}$, cryoglobulinaemia, ulcerative colitis, and iron deficiency anemia, and shed new light on studying the role of cryglobulin in ulcerative colitis, HCV infection and iron deficiency anemia.

\section{Poster Session 3}

Chairperson: Kazuma Fujimoto

P-3-1

\section{Analysis the Status Quo of the Diagnosis and Treatment of 81 Patients with Primary Gastrointestinal Lymphoma}

\author{
Feng Lijuan', Zhang Guoping ${ }^{2}$, Hu Zhongliang ${ }^{3}$, Zou \\ Yiyou ${ }^{1}$, Chen Fengying ${ }^{1}$, Zhang Guiying ${ }^{1}$, Tang Li'an ${ }^{1}$ \\ ${ }^{1}$ Department of Digestive, Xiangya Hospital, Central South \\ University, Changsha; ${ }^{2}$ Department of Hematologist, \\ Xiangya Hospital, Central South University, Changsha; \\ ${ }^{3}$ Department of Pathology, Xiangya Medical College, \\ Central South University, Changsha, China
}

Objective: To analyse the status quo of the diagnosis and treatments of PGIL, and to improve it.

Method: 81 patients with PGIL patients were analyzed retrospectively in clinical manifestations, endoscopic features, pathological features, HP infection, treatment and prognosis.

Results: The average age of patients with gastric lymphoma was $52.84 \pm 15.33$ years old. The average age of patients with intestinal lymphoma was $42.09 \pm 15.28$ years old. Common symptoms included abdominal pain (76.5\%); gastrointestinal bleeding (55.6\%); anemia (54.3\%); abdominal mass (25.9\%); hypoproteinemia $(40.7 \%)$; bowel obstruction (11.1\%); abdominal distension, vomiting, and other non-specific gastrointestinal symptoms (32.1\%); weight loss (33.3\%); fever (8.6\%); diarrhea (7.4\%); digestive tract perforation $(1.2 \%)$; constipation $(1.2 \%)$; dysphagia (1.2\%). Frequent incidence locations were as follows: stomach, small intestine, ileocecal junction, and colon. Endoscopic appearance were as follows: tumor type $67.7 \%$, ulcer type $27.7 \%$, diffuse type $4.6 \%$. Clinical diagnosis rate was $30.9 \%$; clinical misdiagnosis rate was $69.1 \%$. Endoscopic biopsy confirmed rate was $73.8 \%$; biopsy misdiagnosis rate was $26.2 \%$. MALT lymphoma accounted for $61.7 \%$ of the patients. HP detection rate was $39.5 \%$, positive rate was $37.5 \%$. 69 patients received surgeries, 3 patients of which had preoperative chemotherapy, 34 patients had postoperative chemotherapy. 12 patients had non-surgical treatment, 6 patients of which had simple chemotherapy and HP eradication therapy, and the other six patients gave up during treatment. The 5 -year survival rate was $55.87 \%$, the 3 -year survival rate was $70.96 \%$, and the 1-year survival rate was $96.39 \%$.

Conclusion: There are no specific clinical and endoscopic features in PGIL, so the misdiagnosis rate is high. Multi-site biopsy or repeated biopsies and immunohistochemical methods can be used to raise the pathological diagnosis rate. Divergent views are existed in the current treatment modalities, a uniform standard and a set of scientific treatment methods need to be established. There are no significant difference of survival rate in surgery alone, surgery plus chemotherapy, chemotherapy and HP eradication therapy in stage I to stageII patients. Survival rate of surgery alone patients in stage III to stage IV are lower than the other two groups. We recommend chemotherapy and HP eradication therapy first. 
Key words: primary gastrointestinal lymphoma, clinical character, pathological types, Chemotherapy, surgery, prognosis

\section{P-3-2 \\ Effectiveness of Daikenchuto, A Traditional Japanese Herbal Medicine, in Accelerating Capsule Endoscopy Transit Time - A Prospective Pilot Study}

\author{
Konosuke Nakaji ${ }^{1}$, Shigeo Suzumura ${ }^{2}$, Atsuyo Fujita', \\ Mitsutaka Kumamoto1, Yukinori Nakae ${ }^{1}$ \\ ${ }^{1}$ Aishinkai Nakae Hospital, Dept. of Internal Medicine, \\ ${ }^{2}$ Osaka Medical Center for Cancer and Cardiovascular \\ Diseases, Department of Cancer Control and Statistics, \\ Division of Epidemiology
}

Introduction: Currently, there is no consensus on the preparation of patients to improve the passage of CEs through their digestive tract, and the establishment of a standardized preparatory treatment is necessary. The purpose of this study was to investigate whether the pre-exam administration of Daikenchuto shortens the time during which a CE remains in the small intestine, and to improve the speed at which the capsules reach the large intestine.

Methods: We compared a group of 30 patients who received 7.5 $\mathrm{g}$ /day of DKT between lunch and dinner on the day before the endoscopic exam, and at 7:00 a.m. on the day of the exam, versus a group of 105 patients who did not receive DKT. We measured the time for $\mathrm{CEs}$ to remain in the small intestine and their speed in reaching the colon.

Result: A comparison of the remaining curves for CEs from the group that received DKT versus the control group revealed that the time during which the CEs remained in the small intestines was significantly shorter in the group that received DKT (log-rank $\mathrm{P}=0.016)$. Chi-square analysis showed that the group that received DKT had a significantly higher rate of exam completion $(\mathrm{P}=0.0064)$. A Cox proportional model concerning the time through intestinal passage revealed that the proportion of CEs that reached the large intestine was significantly higher in the group that received DKT as compared to the controls $(\mathrm{P}=0.0008)$. The exam completion rate of the DKT group was still significantly higher than the control group after adjusting for age, gender and metoclopramide use $(\mathrm{P}=0.0078)$. DKT did not adversely affect $\mathrm{CE}$ image quality.

Conclusion: These study results suggested that DKT can improve the speed at which the CE reaches the large intestine without compromising exam accuracy by promoting peristalsis of the small intestine.

\section{P-3-3 \\ Protein Losing Enteropathy in Systemic Lupus Erythematosus: A Case Report and Review of the Literature}

Tian Feng

Department of Gastroenterology, Sheng Jing Hospital of China Medical University, Shenyang, China

Protein losing enteropathy (PLE) is a rare manifestation of systemic lupus erythematosus (SLE). PLE is characterized by a leakage of protein from the intestinal tract that results in hypoalbuminemia and genetalized edema. The most common and most easily discovered cause of hypoalbuminemia in SLE is nephrotic syndrome. Besides the pathogenies of PLE-related SLE are complicated and the clinical features are not always representative. Thus, gastrointestinal loss of albumin is harder to investigate and we couldn't pay enough attention to SLErelated PLE. We here report an unusual case of systemic lupus erythematosus presented with protein-losing enteropathy. A 40-year Chinese woman was referred to our hospital with generalized edema, severe hypoalbuminemia at $10 \mathrm{~g} / \mathrm{L}$, hypocomplementemia, hyperlipidemia, elevated CA125 antigen, antinuclear antibody (ANA), anti-Sm antibodies, anti-SSA antibodies and anticardiolipin antibodies positivities, anti-ds-DNA antibody negativities appeared in the blood examination. Her kidney inspection was normal. On the radiological studies, she had a large amount of bilateral pleural effusion, slight pericardial effusion and moderate ascites which were transudate. She was delayed in diagnosis and treatment because she did a long-term tumor investigation for the significantly elevated CA125 level in another hospital. A final diagnosis of PLE-related SLE was made by us on the basis of increased 99mTc-labelled human immunoglobulin scintigram showing abnormal radioactivity. By the administration of methylprednisolone, hypoalbuminemia began to improve slightly, but serum CA125 was increased at $2000 \mathrm{U} / \mathrm{ml}$ after 3 weeks. Serum albumin and CA125 levels were then improved dramatically after weekly intravenous cyclophosphamide combined with oral low-dose prednisone. The low-dose prednisone was used as maintenance medication. Changes of serum albumin and CA125 levels before and after the treatment can be seen in the table. We also present a review of the current literature to raise the recognization of this disease about the pathogenies, clinical manifestation, diagnosis and treatment. Three mechanisms may underlie the pathogenesis of PLE-related SLE. Intestinal mucosa or vascular injury mediated by cytokines (such as tumor necrosis factor- $\alpha$ and interleukin-6) or complement cause plasma protein to leak into the intestinal tract directly. The permeability for proteins of intestinal Mucosa and capillaries are increased. The interstitial edema can squeeze lymph vessel as a result of lymphangiectasia lymphatics. SLE patients having initial symptoms as PLE are rare in the literature, the characteristics of which are hypoalbuminemia, hypocomplementemia, ANA positivity and anti-ds DNA negativities. SLE patients can also have a significantly elevated CA125 level as a result of serosal damage and the shedding of CA125. ${ }^{99 \mathrm{~m}} \mathrm{Tc}$

Table. Changes of serum albumin and CA125 levels before and after the treatment (for Abstract P-3-3)

\begin{tabular}{lcccc}
\hline & pretreatment & $\begin{array}{l}\text { methylprednisolone } \\
80-40 \mathrm{mg} / \text { day }\end{array}$ & $\begin{array}{c}1^{\text {st }} \text { dose cyclophosphamide }+ \\
\text { prednisone 50mg/day }\end{array}$ & $\begin{array}{l}3^{\text {rd }} \text { dose cyclophosphamide }+ \\
\text { prednisone } 50 \mathrm{mg} / \text { day }\end{array}$ \\
\hline albumin $(\mathrm{g} / \mathrm{L})$ & 10.0 & 15.1 & 15.1 & 20.8 \\
CA125 (U/ml) & 1377 & 2000 & 1524 & 667.4 \\
\hline
\end{tabular}


labeled by human serum albumin scintigraphy which can show the leakage of protein from the intestinal tract is the main method of diagnosis now. Corticosteroids can be an effective treatment. Cyclophosphamide or Azathioprine could be used for those patients not sensitive to corticosteroids. PLE must be considered and persistently investigated if excluding other possible causes of protein loss.

\section{P-3-4 \\ Investigate Diagnosis and Treatment of Rectal Carcinoid Tumors}

Zengmin, Wang-shoudong, Liu-liping

Gastroenterology Department, Friendship Hospital of Dalian, China

Introduction: To evaluate the safety and efficacy of endoscopic diagnosis and treatment of rectal carcinoid tumors.

Methods: The clinicial data of 30 patients with rectal carcinod tumors were analyzed retrospectively. Sixteen patients were diagnosed by endoscopic ultrasongraphy, and treated by endoscopic mucoal resecton (EMR).

Result: 16 cases of rectal carcinoid tumors were resected by endoscopic submucosal resection. All the lesions were excised completely. The success rate was $100 \%$. There were no immediate or late complications (bleeding and perforation) after endoscopic submucosal resection. There was no local recurrence and no distant metastases in any patients during follow-up peroid of 3 months to 4 years.

Conclusion: EUS can provide precise information of rectal carcinoid about its size, depth, border, musculcaris propria and vessel infiltration. Endoscopic submucosal resection for the treatment of small rectal carcinoid tumors less than or equal to $1.5 \mathrm{~cm}$ in diameter is a simple, safe and effective therapeutic procedure.

\section{P-3-5}

\section{The Successful Attempt to Perform ESD for Low Grade Dysplasia in Patients with Ulcerative Colitis}

Kenichi Morimoto, K. Watanabe, Y. Ajioka, M. Nishishita, A. Noguchi, S. Sugimori, N. Kamata, M. Sogawa, H. Machida, H. Okazaki, H. Yamagami, T. Tanigawa, K. Tominaga, T. Watanabe, Y. Fujiwara, T. Arakawa

Department of Gastroenterology, Osaka City University, Osaka, Japan

Introduction: The efficacy of surveillance colonoscopy to detect colitis associated cancer or dysplasia (CC/D) for patients with longterm ulcerative colitis is established. Recent investigations show the efficacy of magnifying chromoendoscopy. On the other hand, treatment strategy for dysplasia is controversial, especially for low grade dysplasia, because of confusing criteria for pathological diagnosis. We had recently experienced a rare case of successful ESD resection for low grade dysplasia with detailed colonoscopic and pathological diagnosis.
Methods: A 55-year-old female had suffered from ulcerative colitis (total colitis type) for 42 years. She had ever admitted three times with steroid treatment. She had few symptoms recently. Therefore she had no medication at the previous hospital. After referring to our hospital in 2007, we performed surveillance colonoscopy in 2008. It revealed flat lesion with nodular protrusion in the rectum. We had removed that lesion with EMR. The pathological findings including immunohistochemistry (p53, Ki-67) showed the dysplasia (indefinite for low grade dysplasia or sporadic tubular adenoma) with positive margins. After first colonoscopy in 2008, we performed colonoscopy five times (including one EMR) until 2010. Magnifying chromoendoscopy is helpful to detect the lesion, but it was difficult to point out the definite demarcation line. In the cause of difficulty of complete resection with transanal surgical wedge resection and refusal for open abdominal surgery, we had finally performed ESD with safety margin in 2010 .

Result: The final pathological findings revealed colitis associated low grade dysplasia with negative margin. The findings of immunohistochemistry for $\mathrm{p} 53$ was negative and $\mathrm{Ki}-67$ was positive (bottom-up type). The following colonoscopy with biopsies after six months showed no residual lesion.

Conclusion: The diagnostic criteria of $\mathrm{CC} / \mathrm{D}$ are controversial. The clinicians have to make up clinical managements with detailed colonoscopy with reliable pathologist.

\section{Poster Session 4}

Chairperson: Yuji Naito

\section{P-4-1 \\ Study on the Efficacy and Mechanism of Action of Probiotic Bacteria VSL\#3 on the Model of Experimental Colitis of Rats}

\author{
Min-Jiang \\ Department of Gastroenterology, First Affiliated Hospital \\ of China Medical University, Liaoning, Shenyang, China
}

Objective: Compare the efficacy of probiotic VSL\#3 and traditional medicine mesalazine on acute and chronic experimental colitis of rats. Expression of cytokines (IL-6, IL-23, TGF- $\beta$, STAT3, P-STAT3) and signaling factors that closely related to UC will be detected. The mechanism of probiotic VSL\#3 for treatment will be studied. And its efficacy on experimental colitis will be evaluated.

Methods: Study on chronic experimental colitis of rats was carried out through model of dextran sulfate sodium. 48 rats were randomly divided into 6 groups (including $8 \mathrm{SD}$ rats from normal control group; 8 rats in each group): L-R group. Observed indexed, collection and processing of specimens.

Results: Comparison of appearance and length changed of rats' large intestines: The colons of rats in normal group were reddish with forming of feces in intestinal cavity. There was a congestive appearance of colons of rats in model and NS group with formless and loose stool in intestinal cavity mostly. There was a different degree of thinning of intestinal wall of the rats' drunk DSS solution. There was vary- 
ing degrees of shorten of the length of large intestines. The degree of shorten of the length of large intestines of the rats in each group from high to low was NS group, model group, inactivated VSL\#3 group, VSL\#3 group, mesalazine group, combined treatment group. There was a significant difference on shorten of the length of large intestines among inactivated VSL\#3 group, VSL\#3 group and mesalazine group, but no significant difference among them. Compared with the single-agent group, the least shorten in combined treatment group had a significant difference.

About the DAI score, DAI score of each group were slowly reduced from Day 1 to 4 . There was no significant difference among the DAI score of each group. From Day 5, there was a significant difference among the DAI score of each group gradually. On Day 7, DAI score from high to low was model group, NS group, VSL\#3 group, inactivated VSL\#3 group, mesalazine group, combined treatment group. There was no significant difference between model group and NS group. DAI scores of VSL\#3 group, inactivat- ed VSL\#3 group, mesalazine group were significantly lower than model group, but no significant difference on DAI score among the three treatment groups. The lowest DAI score in combined treatment group was significantly lower than single-agent treatment group, which had a significant difference,

Score of histology injury: Score of histology injury of the rats in normal group was 0 . There was a different degree of injury of remaining six groups of rats. Score of histology injury from high to low was NS group, model group, mesalazine group, VSL\#3 group, inactivated VSL\#3 group, VSL\#3 + mesalazine group. There was no significant differ- ence among VSL\#3 group, mesalazine group and inactivated VSL\#3 group. There was a significant difference between mesalazine - VSL\#3 combined treatment group and each single-agent treatment group.

Cytokines: IL-23, IL-6, TGF- $\beta$.

The three cytokines above were detected by Real-Time PCR and Western Blotting. The highest expression of mRNA level and protein level was in model group, followed by NS group, that there was no significant difference between them. The expression of three cytokines in mesalazine group was signifi- cantly lower than model group. There was no significant difference on the expression of three cytokines between VSL\#3 group and heat-inactivated group. The expression in mesalazine - VSL\#3 combined treatment group was significantly lower than single-agent treatment group.

Signal factors related to cell differentiation: STAT3 and P-STAT3. mRNA level, protein level and immunohistochemical IOD of two indicators above showed that the highest expression in model group, followed by NS group, but there was no significant difference between them. The expression in mesalazine group was significantly lower than model group. There was no significant difference on the expression of STAT3 and P-STAT3 among VSL\#3 group, heat-inactivated VSL\#3 group and mesalazine group. The lowest expression in mesalazine - VSL\#3 combined treatment group was significantly lower than single-agent treatment group.

Conclusions: Probiotic VSL\#3 and heat inactivated VSL\#3 have a certain efficacy on acute and chronic experimental colitis, which is equally to traditional medicine adis. And there is no significant difference among the three. Probiotic VSL\#3-mesalazine combined treatment has the best efficacy on acute experimental colitis. The expression of cytokines (IL-23, IL-6, TGF $\beta$ ) in STAT signal transduction system and signal factors related to cell differentiation (STAT3 and P-STAT3) in probiotic VSL\#3 group, heat-inactivated VSL\#3 group, mesalazine group, VSL\#3-mesalazine combined treat- ment group decreases significantly, which has a positive correlation with the severity of rats' colitis. VSL\#3-mesalazine combined treatment group has the lowest expression level.

Key words: ulcerative colitis; STAT; TGF- $\beta$

\section{P-4-2 \\ Identification of Aberrantly Expressed microRNAs in Rectal Cancer and Its Clinical Significance}

\author{
Xinhua $L i^{1}$, Wei Wu ${ }^{2}$, Oian $L i^{1}$, Meihua X ${ }^{1}$, Deyun Feng ${ }^{3}$, \\ Guiying Zhang ${ }^{1}$ \\ ${ }^{1}$ Department of Gastroenterology, ${ }^{2}$ Department of \\ Geriatric Surgery, Xiangya Hospital, and ${ }^{3}$ Department of \\ Pathology, Xiangya School of Medicine, Central South \\ University, Changsha, Hunan, P.R. China
}

Introduction: Disturbance of microRNA expression may play a key role in the initiation and progression of colorectal cancer (CRC). CRC should be viewed as a heterogeneous disease, but previous studies only screened dysregulated miRNAs in CRC from a panel of 96, 145,287 and 455 miRNAs respectively. It is completely necessary to identify new aberrant expression miRNAs in rectal cancers.

Methods: The tissue samples were derived from patients undergoing a surgical procedure to remove a portion of cancers. A microRNA expression profile had been analyzed by miRCURYTM LNA Array (v.14.0) between 6-paired rectal cancers and normal tissues. Expression levels of 4 miRNAs were compared by real-time PCR between colon and rectal cancers, and also analyzed their expression levels in different stages of rectal cancers.

Result: 88 microRNA precursors are upregulated expression in rectal cancers $(\mathrm{p}<0.05)$ and 20 microRNAs have never been reported in colorectal cancer (CRC); 43 microRNA precursors are downregulated expression $(\mathrm{p}<0.05)$ and identified 24 novel dysregulated microRNAs in the rectal cancer. miR-31, miR-126 and miR-143 are differently express between colon cancers and rectal cancers. miRNA-31 and miR-145 dysregulated expression levels are related with different pathological stages of rectal cancers.

Conclusion: Here we report miRNA profile in rectal cancer, and miRNA-31 and miR-145 are associated with progression of rectal cancers. This novel information may suggest the potential roles of these miRNAs in the diagnosis of rectal cancers. 


\section{P-4-3 \\ Expression of Transforming Growth Factor $\beta$ Receptor II in Colorectal Cancer and Its Relationship to CyclinD}

Wang Zhaohui, Zhang Xuemei

Department of Gastroenterology, Dalian Municipal Central Hospital, Dalian, China

Introduction: To study the expression of transforming growth factor $\beta$ receptor II (TGF- $\beta$ RII) and CyclinD $_{1}$ in colorectal adenoma and colorectal cancer, and to explore the mechanism of them in the pathogenesis of colorectal carcinoma.

Methods: 56 colorectal cancers, 29 colorectal adenomas and 56 corresponding cancer-adjacent normal tissues were explored by immunohistochemistry for the expression of TGF- $\beta$ RII and CyclinD ${ }_{1}$.

Result: The expression of TGF- $\beta$ RII was distributed mainly in the membrane and cytoplasm, The expression of TGF- $\beta$ RII (44.64\%) was lower than that of adenoma $(82.76 \%)$ and normal tissues $(96.43 \%)$ $(\mathrm{P}<0.01)$. The expression of $\mathrm{CyclinD}_{1}$ was distributed mainly in the nuclear. The expression of CyclinD $_{1}$ in colorectal cancers $(89.29 \%)$ was significantly higher than that of adenoma (41.38\%), and there was no overexpression in normal colorectal tissues. The overexpressio of CyclinD $_{1}$ can significantly reduced the expression of TGF- $\beta$ RII.

Conclusion: The lower expression of TGF- $\beta$ RII and overexpressio of $\mathrm{CyclinD}_{1}$ may play an important role in the carcinogenesis of colorectal cancer.

Key words: transforming growth factor $\beta$; receptor; $\mathrm{CyclinD}_{1}$; colorectal cancer

\section{P-4-4 \\ Human Umbilical Cord Mesenchymal Stem Cells Ameliorate Mice Colitis by Regulating the Balance of Th1/Th2 and Tregs/Th17}

Yan Lin

Gastroenterology \& Shengjing Hospital of China Medical University

Introduction: Inflammatory bowel disease (IBD), which includes Crohn's disease and ulcerative colitis, is an inflammatory autoimmune disease. Mesenchymal stromal cells (MSC) have both multilineage differentiation capacity and immunosuppressive properties, have emerged as a promising candidate for cellular therapeutics for IBD. In this study we investigated whether human umbilical cordderived mesenchymal stem cells (hUC-MSC) could ameliorate colitis in a trinitrobenzene sulfonic acid (TNBS)-induced colitis model.

Methods: TNBS-treated colitic mice were infused with hUCMSC or vehicle control. The mice were sacrificed on day 3 and 5 after infusion, and their clinical and pathological conditions were evaluated by body weight, DAI score and histological analysis. The expression of pro-inflammatory cytokine proteins in colon were examined by ELISA. The gene expression levels of pro-inflammatory cytokine in colon were examined by Real-time PCR. The expression of $\mathrm{CD} 4{ }^{+} \mathrm{CD} 25^{+}$Tregs of mesenteric lymph nodes (MLN) cells were examined by flow cytometer. The homing of hUC-MSC was studied by live in vivo imaging and immunofluorescent microscopy.

Result: Our results showed hUC-MSC were found to migrate to the inflamed colon and ameliorates the colitics with improved clinical and pathological signs. hUC-MSC promoted noninflammatory $\mathrm{Th} 2$ (IL-10, TGF- $\beta$, IL-4) response and decreased inflammatory Th1 (IL$1 \beta$, INF- $\gamma$, IL-6, IL-12, TNF- $\alpha$ ) and Th17 (IL-17, IL-23) response. hUC-MSC induced the conversion of naïve T-cells into functional $\mathrm{CD} 4^{+} \mathrm{CD} 25^{+} \mathrm{Foxp}^{+}$Tregs.

Conclusion: hUC-MSC could home to the inflamed colon and effectively ameliorate colitis. hUC-MSC-mediated modulation of the balance of Th1/Th2 and Th17/Tregs plays an important role in the amelioration of colitis. These data underscore the potential of using hUC-MSC to control inflammatory bowel disease and demonstrate its potential use in future human therapeutic settings.

\section{P-4-5 \\ Intravenous Injection of Bone Morphogenetic Protein in the Treatment of DSS-Induced Colitis}

\author{
Weixin Liu, Weiyu Liu, Hongming Lin, Zheng Zhou, \\ Qingmin Zhang \\ Department of Gastroenterology, the 1st affiliated \\ Hospital, China Medical University, Shenyang City, China
}

Introduction: The etiology of inflammatory bowel diseases (IBD) is uncertain; Bone morphogenetic protein (BMP) is a growth and differentiation factor and belongs to the TGF-beta super family of proteins. Previous studies have shown an abundant expression of BMP-7 in the developing intestine and an association with a perturbed $\mathrm{BMP} / \mathrm{SMAD}$ downstream signaling leading to a malignant phenotype and inflammation. The aim of this study was to investigate the therapeutic effect of BMP in a murine model of colitis which is induced by feeding of Dextran Sodium Sulfate (DSS), an often-used animal model mimicking clinical and histological features of human IBD.

Methods: We examined the therapeutic action of BMP in the colitis induced drinking DSS evaluating diverse clinical signs of the disease including weight loss, diarrhea, colitis, and histopathology. We also investigated the mechanisms involved in the potential therapeutic effect of BMP, such as inflammatory cytokines and chemokines, generation of regulatory $\mathrm{T}$ cells.

Result: BMP injection significantly ameliorated the clinical and histopathologic severity of colitis, abrogating body weight loss, diarrhea, and inflammation, and increasing survival. The therapeutic effect was associated with down-regulation of inflammatory response, by regulating a wide spectrum of inflammatory mediators directly through activated macrophages.

Conclusion: Treatment with BMP has effect on the systemic and mucosal immune responses resulting in reduced intestinal inflammation and abrogates colitis-induced weight loss. This generates the possibility of BMP for the treatment of Colitis induced by in mice.

Key words: DSS induced colitis, Dextran Sodium Sulfate, Teatment, IBD 


\section{P-4-6 \\ Diagnostic Value of Simultaneous \\ Determination of Tumor Markers in Ascitic \\ Fluid and Serum and their Ratios for \\ Differentiation Benign from Malignant \\ Ascites}

Xu Mei-hua, Deng Xiang-yu, Zhang Gui-ying

Department of Gastroenterology of Internal Medicine, Xiangya Hospital, Central-South University, Changsha, China

Introduction: To evaluate the clinical diagnostic value of simultaneous determination of tumor markers in fluid and serum and their ratio $(\mathrm{F} / \mathrm{S})$ to patients with benign or malignant ascites.

Methods: Retrospective analysis the concentrations of tumor markers AFP, CEA, CA19-9, CA125 in fluid and serum and their ratio from 95 patients with ascites, due to various causes of malignant 52 and benign 43.

Result: 1. The levels of ascitic fluid CEA, CA19-9, CA125 and the blood serum AFP, CEA, CA19-9 in patients with malignant ascites were significantly higher than those in patients with benign ascites $(P<0.001) ; 2$. According to the ROC (receiver operating characteristic, ROC) curve, the under-curve area of fluid AFP, CEA, CA19-9 and CA125 were $0.510,0.825,0.773$ and 0.500 . It showed that CEA and CA19-9 could be used for differential malignant from benign ascites; 3 . The sensitivity, specificity and diagnostic accuracy of the combined detection of these two tumor markers and their F/S ratios were $94.2 \%, 90.7 \%$ and $92.6 \%$. The diagnostic sensitivity and accuracy were obviously improved $(P<0.01) ; 4$. The sensitivity, specificity and diagnostic accuracy of fluid CEA were $67.3 \%, 95.3 \%$ and $80.0 \%$, CA19-9 in ascites fluid were $61.5 \%, 93.0 \%$ and $75.8 \%$. Combined detection of the two tumor markers were $78.8 \%, 90.7 \%$ and $84.2 \%$, their $\mathrm{F} / \mathrm{S}$ ratios of the combined detection of these two tumor markers were $94.2 \%, 90.7 \%$ and $92.6 \%$, which the diagnostic sensitivity and accuracy were obviously improved $(P<0.01)$.

Conclusion: 1. The fluid CEA and CA19-9 were more valuable than AFP for differentiation of benign from malignant ascites, CA125 had no value for differentiation of benign from malignant ascites; 2 . The diagnostic sensitivity and accuracy could be significantly increased by simultaneous determination of the concentration of CEA, CA19-9 in fluid and their F/S ratio.

\section{Poster Session 5}

Chairperson: Kenji Furuta

P-5-1

Bone Morphogenic Protein-7 (BMP-7) Opposes the Fibrogenic Activity of TGF- $\beta_{1}$ on Rat Model of Liver Fibrosis

\author{
Lan Zhong*, Shenglan Wang, Li Yang, Hengjun Gao, \\ Changqing Yang ${ }^{\#}$
}

Division of Gastroenterology and Institute of Digestive Disease, Tongji Hospital, Tongji University School of

Medicine, Shanghai, China

Introduction: Transforming growth factor- $\beta 1$ (TGF- $\beta 1$ ) plays an important role in the pathogenesis of liver fibrosis and cirrhosis. Bone morphogenic protein-7 (rhBMP-7), a member of the TGF- $\beta$ superfamily, has been reported to atagonist the activity of TGF- $\beta 1$, and has been proved to alleviate renal fibrosis and improve kidney function. However, whether rhBMP protects the liver in variable chronic insults remains unknown. The purpose of the present study is to investigate the prophylactic and therapeutic effects of rhBMP on liver fibrosis and the possible mechanisms.

Methods: Fibrotic model was induced by peritoneal injection of porcine-serum $(0.5 \mathrm{ml} / \mathrm{kg}$ body wt ip, need to adjust to body weight) $2 \mathrm{x} / \mathrm{wk}$ for $8 \mathrm{wk}$, the prophylactic and therapeutic effects of rhBMP-7 were investigated by the comparison of rhBMP-7 treated rats with fibrotic control group. Histology change was assessed by HE staining, the anti-fibrotic mechanism of rhBMP was explored in hepatic stellate cells (HSC). TGF- $\beta 1$, SMAD3 and collagen I III IV expressions were evaluated by real-time RT-PCR, Western blotting and enzyme-linked immunosorbent assay (ELISA).

Result: rhBMP-7 significantly alleviated the degree of liver fibrosis; rhBMP-7 decreased the secretion of collagen I, III in HSC. rhBMP-7 not only inhibited the nuclear accumulation of $\operatorname{smad} 2 / 3$, but also inhibited the expression of TGF $\beta_{1}$.

Conclusion: rhBMP-7 exerts antifibrogenic effects via downregulation of TGF $\beta_{1}$ expression and intracellular signal transduction of Smd2/3 in HSC. Many aspects of BMP-7 therapy in liver fibrosis remain to be investigated in more details.

\section{P-5-2 \\ Study on Intratumor Injection of Octreotide Temperature-Sensitive Gel for the Treatment of Liver Cancer in Mouse \\ Zhijun Duan, Lili Zhang, Su Yu, Ge Tian, Yan Tian \\ Gastroenterology Department, First Affiliated Hospital of \\ Dalian Medical University, Dalian, China}

Introduction: OCT (octreotide) can inhibit tumor with little side effect, and it is supposed that plolxamer 407 as a temperature- 
sensitive gel added could make up for its short half life time. The study was aimed to determine a new preparation of intratumor injection for the patient at end stage of liver cancer.

Methods: By Cell culture, the proliferation and apoptosis of Hca-F liver cancer cells was determined with MTT colorimetric method and flow cytometry. Mouse model of subcutaneous transplant tumor was built and OCT-P407 or OCT solution was injected into the tumor separately $(n=8)$ under the guide of ultrasound, then OCT contents in tumor were detected by high performance liquid chromatography (HPLC) after12, 24 and $48 \mathrm{hs.} \mathrm{OCT-P407,} \mathrm{Ethanol,} \mathrm{OCT,}$ P407 or NS was separately injected to the tumor (each $n=10$ ) and after $8 \mathrm{wks}$, the size, weight and inhibition rate were measured, moreover, Immunohisto-chemistry and RT-PCR were used to detect the expression of somatostatin receptors-2 (SSTR-2), Vascular endothelial growth factor (VEGF) and Cysteine aspartic acic specific protease 3 (Caspase-3).

Result: Compared with OCT group, inhibition rates of OCT-P407 group were high and its inducing apoptosis showed obvious, and the effects persisted longer. The OCT content of OCT-P407 group detected after $12 \mathrm{hs}$ increased, and could still be monitored at 24 and 48 hours, while that of the OCT group could not be detected. The tumor size of OCT-P407 group was smaller than that of OCT, P407, and NS group, and its weight also was lesser $(\mathrm{P}<0.05)$, moreover, its inhibitory rate was $61 \%$, obviously higher. However, compared with Ethanol group, its weight was heavier and inhibitory rate was lower $(\mathrm{P}<0.05)$. The protein and gene expressions of SSTR-2 and Caspase-3 of OCT-P407 group were reduced, but did not show different from Ethanol group. And VEGF protein expression displayed the similar result between the groups. However, the VEGF gene expression of OCT-P407 group was higher than that of the Ethanol group $(\mathrm{P}<0.05)$.

Conclusion: OCT-P407 intratumor injection can maintain the local effective concentration and prolong the response time of OCT, and its curative effect is better than OCT solution. Its inhibitory effect is similar with Ethanol in some respects though the latter total results shows better.

\section{P-5-3}

\section{Comparison of Endoscopic Papillary Large Balloon Dilation and Endoscopic Sphincterotomy for Retrieval of Choledocholithiasis: A Meta-Analysis of Randomized Controlled Trials}

\author{
Yadong Feng, Hong Zhu, Xiaoxing Chen, Shunfu Xu, \\ Wenfang Cheng, Jinliang Ni, Ruihua Shi \\ Gastroenterology Department of the First Affiliated \\ Hospital of Nanjing Medical University, China
}

Introduction: Endoscopic sphincterotomy (EST) is the most frequently used technique for removal of stones from the bile duct. In recent years, endoscopic papillary large balloon dilation (EPLBD) has been shown to be a safe and effective technique for the removal of large or difficult common bile duct stones. However, comparison of EPLBD and EST for effectiveness in bile duct stone removal has given inconsistent results. The present meta-analysis was carried out to compare the effect of EPLBD and EST in retrieval of choledocholithiasis.
Methods: A literature search was performed using Medline, PubMed, EMBase and the Cochrane Central Register of Controlled Trials (CENTRAL) for relevant articles published in English. A metaanalysis was performed on the retrieved studies.

Result: Seven randomized controlled trials and 790 patients were involved. EPLBD compared with EST resulted in similar outcomes for overall successful clearance rates of bile duct stones $(97.35 \%$ vs. $96.35 \%, \mathrm{OR}=1.28,95 \% \mathrm{CI}=0.58$ to $2.82, \mathrm{P}=0.54)$, stone clearance in the first ERCP session $(87.87 \%$ vs. $84.15 \%, \mathrm{OR}=1.31,95 \% \mathrm{CI}=0.81$ to $2.11, \mathrm{P}=0.21)$ and removal of large sized stones $(\mathrm{OR}=1.08,95 \%$ $\mathrm{CI}=0.21$ to $5.64, \mathrm{P}=0.49$ ). EPLBD performed with either a short or a long ballooning time did not increase the bile duct stone clearance rate. EPLBD decreased overall usage of mechanical lithotripsy in the bile duct stone removal process $(\mathrm{OR}=0.51,95 \% \mathrm{CI}=0.30-0.86$, $\mathrm{P}=0.01$ ). However, no significant difference was found between EPLBD and EST in the use of mechanical lithotripsy for the removal of large sized stones $(\mathrm{OR}=0.67,95 \% \mathrm{CI}=0.34$ to $1.28, \mathrm{P}=0.22)$. Compared with EST, EPLBD did not show a short ERCP duration ( $\mathrm{WMD}=-0.75,95 \% \mathrm{CI}=-1.57$ to $0.08, \mathrm{P}=0.08$ ). EPLBD was associated with fewer overall complications than EST (5.8\% vs.13.1\%, $\mathrm{OR}=0.41,95 \% \mathrm{CI}=0.24$ to $0.68, \mathrm{P}=0.0007)$. Hemorrhage occurred less frequently with EPLBD than with $\mathrm{EST}(\mathrm{OR}=0.15,95 \% \mathrm{CI}=0.04$ to $0.50, \mathrm{P}=0.002$ ). There was no significant difference in post-ERCP pancreatitis, perforation and cholangitis.

Conclusion: EPLBD is an effective and safe method for the removal of common bile stones. EPLBD should be considered as an alternative to EST for patients in whom EST could not be routinely performed. Based on EPLBD causing fewer cases of hemorrhaging, EPLBD is also recommended in patients with an underlying coagulopathy or need for anticoagulation following ERCP. The efficiency and long-term prognosis of EPLBD need to be further investigated.

\section{P-5-4 \\ An Eosinophilic Cholangitis Case Report with a Review of Associated Literatures}

Haoqing

\author{
Gastroenterology Department of Shengjing Hospital \\ Affiliated to China Medical University, Shenyang, Liaoning \\ Province, China
}

Many conditions, such as stones and tumors in the bile duct or the head of pancreas, carcinoma of ampulla, biliary ascariasis and so on, can cause acute cholangitis. The bile duct was obstructed due to above factors, then the bile drainage is blocked. The following events are the edema and secondary infection of the bile duct. But the inflammatory stenosis of the bile duct due to the increase of eosinophils is really rare in clinical practice. Here we report such a case admitied to our department:

A 61-yrs-old man, a retired worker who resides in the city without allergic history and special substances contact history had suffered from the abdominal pain and distention for two months before his hospitalization, accompanying with nausea, vomit of gastriccontent, watery stool with no pus and blood in it. Antidiarrheal proved to be useless. He did not show any improvement even after 1 week's treatment as "ischemicenteropathy" at the local hospital. 


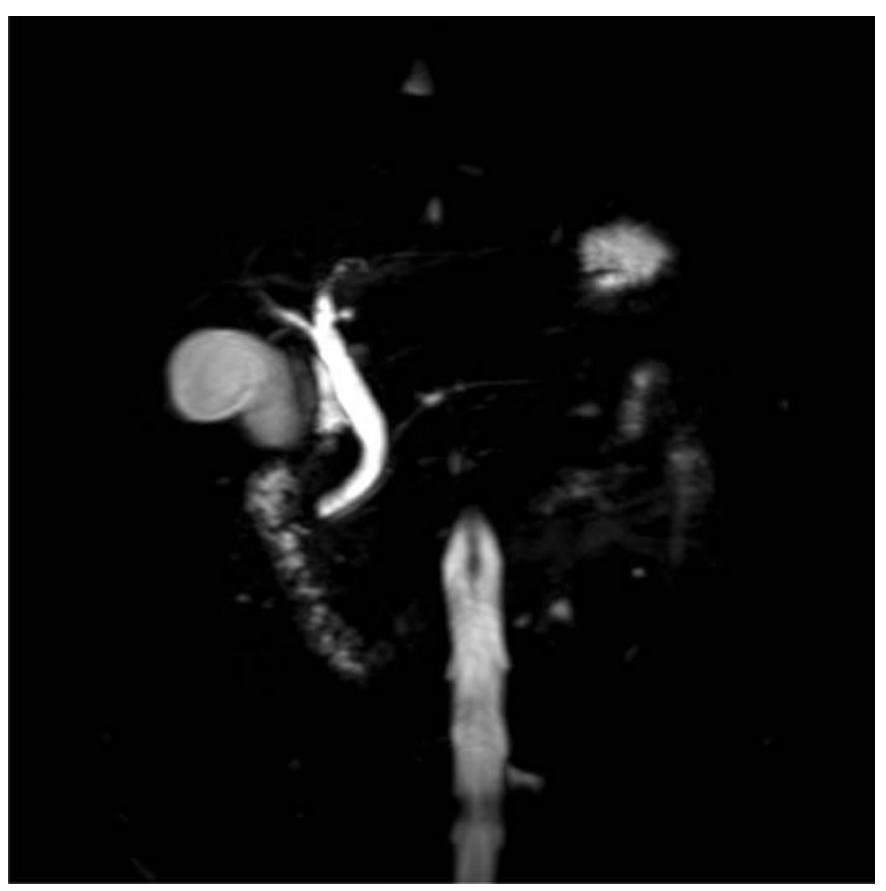

Fig. 1. Narrowing of the lower part of bile duct.

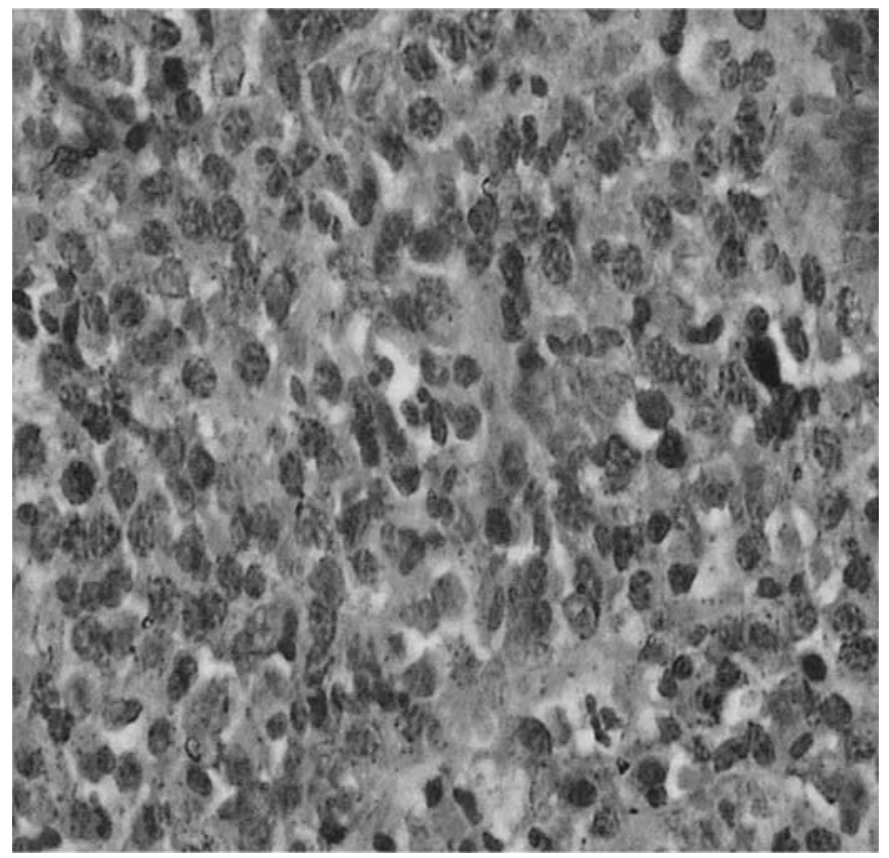

Fig. 2. Eosinophil infiltration in the colon mucosa.

Physical examination: tenderness of epigastrium, with no other positive signs.

The acid-inhibition and anti-inflammatory treatments were carried out to the patient. But curative effect was poor. The abdominal pain and distention aggravated progressively, nausea and vomit frequently.

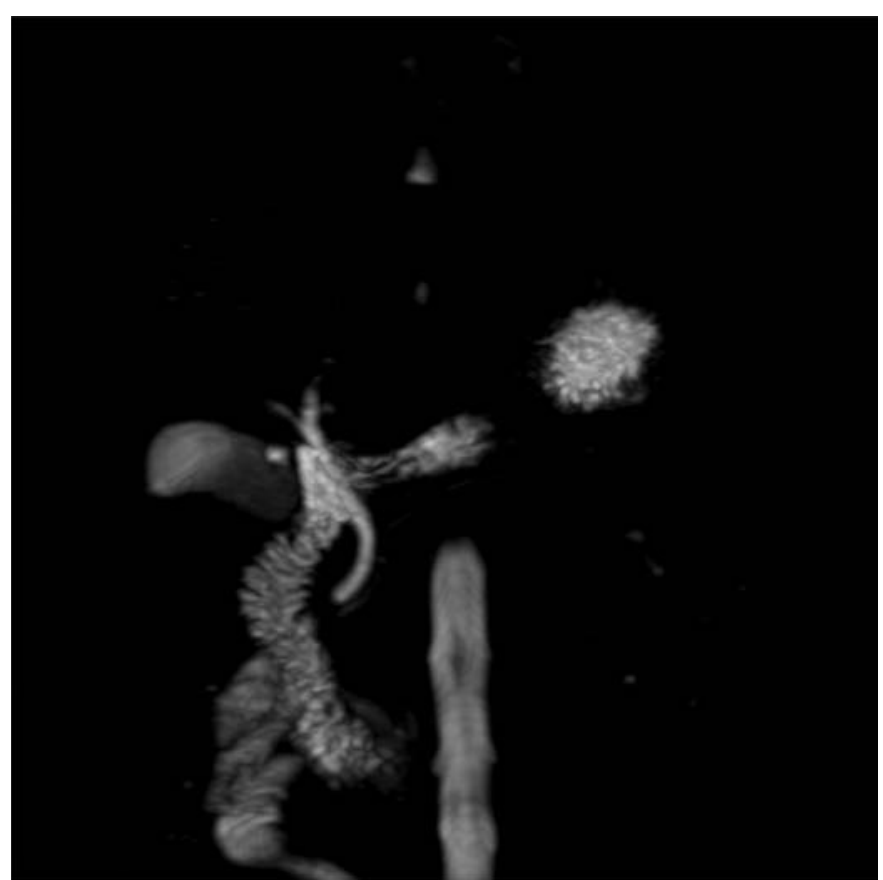

Fig. 3. The bile duct recovered to normal after glucocorticoid treatment.

During the treatment his eyes even became yellow. The following lab test showed the serum amylase and lipase increased significantly. The abdominal ultrasonography, CT and MRCP all indicated a distended thick-walled gall bladder and the upper common bile duct dilated to $1.6 \mathrm{~cm}$ in diameter due to the narrowing of the lower bill duct picture-1. No stone and tumor was found in the bill duct. So we deduced that it was the inflammatory that caused the narrowing of the lower bill duct. At the same time the endoscopy of colon was carried out. The colon mucosa was edematous and congestive under endoscopy and the biopsy of the colon mucosa showed infiltration of massive eosinophils (picture-2). The blood routine tests of those days also indicated that eosinophils in the peripheral circulation increased progressively. For further examination we carried out bone marrow puncture, and the result showed eosinophilia in the bone marrow. Till then the final diagnosis of eosinophilic cholangitis was clear.

Treatment: methylprednisolone $40 \mathrm{mg}$ per day. Five days latter, the GI tract symptoms alleviated obviously, and the serum amylase and lipase decreased to normal level. Then the patient was discharged with oral administration of prednisone. The prednisone was reduced gradually to stop. The MRCP examination after 1 month of glucocorticoid withdrawl indicated that the narrowing of lower bill duct disappeared completely, and the size of gall bladder recover to normal (picture-3).

Discussion: Kinds of etiologies such as parasites infection, hypersensitiveness disease, anaphylactic reaction and so on, can cause the increasing of eosinophil [1]. The increased eosnophil can recover to normal after the eradication of above etiologies.

Eosinophilic cholecystitis or cholangitis are really rare not only in the clinical practice but also in the literatures. One of such rare conditions was first described in 1949 and was characterized by dense, transmural eosinophils infiltration of the gall bladder wall [2]. Few 
cases have been reported since then. Shakov R [3] had reported a case of a 29-yrs old male whose cholecyst was removed due to the continuous pain of the right upper quadrant and chill after diagnosed as "acute cholecystitis" by abdominal ultrasonography. On histopathological examination of the specimen a pure submucosa infiltration of numerous eosinophils in the gall bladder tissue was seen and a final diagnosis of eosinophilic cholecystitis was made. In this patient the peripheral eosinophil count is normal that made diagnosing difficult. Eosinophilic cholecystitis can occur alone, or in combination with cholangitis.

The clinical manifestations of eosinophilic cholecystitis or cholangitis are completely same with other kinds of cholecystitis or cholangitis. So it is difficult to differentiate them only on clinical manifestations, although it is very easy on histopathological examination. Few associated cases diagnosis reported in the literature were all confirmed in the histopathological examination after surgery. If the right diagnose can be made promptly, glucocorticoid will bring completely remission and the surgery can be avoided.

The case in our report is just such a patient who escaped from the surgery because of the correct and timely diagnosis. But the diagnosing experience proved to be difficult. The GI tract symptoms become worse by routine treatment. Then the abdominal Radiological examinations showed two important clues: the first one is the edema of the colon mucosa and massive eosinophils infiltration in submucosa under microscope. The other one is the narrowing of the end of common bile duct but no stone and tumor were found there. At the same time the eosinophil count in the periphery blood was found increased significantly. The infiltration of eosinophils in the colon mucosa lead us to believe that the narrowing of the common bile duct was also the results of the infiltration of eosinophils in the location. Then the diagnosis of eosinophilic cholangitis was made and the glucocorticoid was administrated to the patient. The symptoms were improved very soon after the glucocorticoid was used. 1 month later after glucocorticoid withdrawl, MRCP showed the completely recover of the bile duct. But there is still a pity for this case, for we have no pathologic evidence for the diagnosis because no surgery was done.

Key words: eosinophilic cholecystitis, case report, review

\section{References}

1. Jianzhong $\mathrm{Ma}_{\mathrm{o}} 27$ cases of eosinophilia in children, The Journal of Practical Medicine, 2006;22(1):1291.

2. Albot G, Olivier C, Libaude H. Les cholecystitis eosinophils. Presse Med. 1949;57:558-9.

3. Shakov R, Simoni G, Villacin A, Baddoura W. Eosinophilic cholecystitis, with a review of the literature. Ann Clin Lab Sci. 2007 Spring; 37(2):182-5.

\section{P-5-5}

\section{The Relation between Human Papillomavirus and Pancreatic Carcinoma}

\section{Gao Ming-yu, Liu Dong-mei \\ Department of Gastroenterology, Liaoning Electric Power Central Hospital, Shengyang, China}

Introduction: To investigate the presence of human papillomavirus (HPV) in pancreatic carcinoma and to explore the correlation of the viral infection and the disease.

Methods: Thirty-nine patients with paraffin-embedded from pancreatic carcinoma were studied. Tissues were initially analyzed through MY/GP nested polymerase chain reaction (PCR) to detect the HPV L1 gene. Direct DNA sequencing was conducted to confirm positive PCR results. Positive control application has confirmed the existence of HPV infection in cervical swab clinical specimens.

Result: HPV DNA was not detected in pancreatic specimens of 39 patients with cancer.

Conclusion: No correlation between the presence of the virus and pathogenesis of the pancreatic carcinoma was observed.

\section{P-5-6 \\ The Analysis of Liver Cirrhosis Blood Lipids \\ Jing Chi \\ The First Affiliated Hospital of Chinese Medical University, China}

Introduction: To study serum lipids comparative analysis of different types different classification in patients with liver cirrhosis. Methods: 114 patients with liver cirrhosis were selected from clinical data collection and statistics, comparing to different types, different child-pugh liver cirrhosis in blood lipid. Results: the lipid levels with child-pugh classification increasing, the lipid levels gradually reduce $(\mathrm{P}<0.05)$; Different types with liver cirrhosis, lipid levels have no obvious difference $(\mathrm{P}>0.05)$; Conclusion: lipid levels is an index which reflects to the damage degree of liver function; Different types of patients with liver cirrhosis lipid levels without difference, but are lower than normal level.

Methods: 114 patients with liver cirrhosis were selected from clinical data collection and statistics, comparing to different types, different child-pugh liver cirrhosis in blood lipid.

Result: the lipid levels with child-pugh classification increasing, the lipid levels gradually reduce $(\mathrm{P}<0.05)$; Different types with liver cirrhosis, lipid levels have no obvious difference $(\mathrm{P}>0.05)$.

Conclusion: lipid levels is an index which reflects to the damage degree of liver function; Different types of patients with liver cirrhosis lipid levels without difference, but are lower than normal level. 
Abdullah, M. O-3-5, O-3-6

Abe, K. P-1-4

Abe, N. O-4-1

Abei, M. O-3-2

Adachi, Y. O-2-5

Ahn, J.Y. O-3-3, P-2-3

Ajioka, Y. P-3-5

Akaike, T. O-1-2

Akazawa, Y. O-2-1

Amagase, K. O-4-1

Amano, Y. O-4-4

Anjiki, H. P-1-4

Arakawa, T. P-3-5

Arimura, Y. O-2-5

Bae, S.E. O-3-3

Calin, G.A. O-5-4

Chen, X. P-5-3

Cheng, W. P-5-3

Choi, J.Y. O-3-3, P-2-3

Choi, K.-S. O-3-3, P-2-3

Choi, K.D. O-3-1, O-3-3, P-2-3

Choi, K.S. O-2-2, O-2-3, O-5-2

Chung, J.W. O-2-3, P-2-5

Chung, Y.G. O-2-3

Dong-mei, L. P-5-5

Du, Y. O-2-4

Duan, Z. P-5-2

Duanmin, H. O-4-5

Endo, S. O-3-2

Endo, T. O-2-5

Fauzi, A. O-3-5, O-3-6

Feng, D. P-4-2

Feng, T. P-3-3

Feng, $\mathrm{X}$. O-4-3

Feng, Y. P-5-3

Fengying, C. P-3-1

Fujita, A. P-3-2

Fujiwara, Y. P-3-5

Fukuba, N. O-4-4

Fukuda, K. O-3-2

Fukui, H. O-1-3

Gao, H. P-5-1

Gong, Y. O-2-4

Gui-ying, Z. P-1-6, P-1-3, P-3-1, P-4-6

Guoping, Z. P-3-1

Gyenge, M. O-4-1
Hahm, K.B. O-2-3, O-2-2, O-5-2, P-2-5

Han, Y.-M. O-2-2, O-5-2

Handa, O. O-5-3

Haoqing, P-5-4

Harusato, A. O-5-3

Hayashi, T. O-2-1

He, X.M. P-2-1

He, Y. P-1-1

Heo, S.J. P-1-2, P-2-2

Hibi, T. O-1-2

Hirayama, T. O-2-1

Hong, H. O-2-3, O-2-2, O-5-2

Hong, K.S. O-2-2, O-2-3, O-5-2

Hossain, S. O-1-2

Huang, Y. P-2-6

Hui-Li, C. O-5-1

Hyodo, I. O-3-2

Ichikawa, T. O-2-1

Inamori, M. O-3-4

Ishige, K. O-3-2

Ishihara, S. O-4-4

Ishii, T. P-1-4

Ishikawa, T. O-5-3

Isomoto, H. O-2-1

Jiang, M. P-2-6

Jiang, W.-G. O-5-5

Jie, P. P-1-6

Jin, Y. O-5-5

Jing, C. P-5-6

Juan, W. P-1-3

Jung, H.-Y. O-3-3, O-3-1, P-2-3

Jung, J. O-3-1

Jung, J.-H. O-3-3

Kamada, K. O-5-3

Kamata, N. P-3-5

Kamiya, N. O-1-3

Kaneko, T. O-3-2

Kanho, R. O-3-2

Katada, K. O-5-3

Kim, D.H. O-3-3, P-2-3

Kim, E.-H. O-2-2, O-2-3, O-5-2

Kim, J.H. O-2-3, O-3-3, O-5-2, P-2-3, P-2-5

Kim, M.-Y. O-3-3, P-2-3

Kim, S.-S. O-2-2

Kim, Y.J. O-2-3, O-5-2, P-2-5

Kinoshita, Y. O-4-4

Kohtani, T. O-4-2

Koide, T. O-3-4
Kokura, S. O-5-3

Konishi, H. O-5-3

Kumamoto, M. P-3-2

Kusunoki, R. O-4-4

Kuyama, Y. P-1-4

Kwon, K.A. P-2-5

Lee, G.H. O-3-3, P-2-3

Lee, H. P-1-2, P-2-2

Lee, J.H. O-3-3, P-2-3

Lee, J.J. O-5-2, P-2-5

Lee, S.K. O-5-4, P-1-2, P-2-2

Lee, Y.C. P-1-2, P-2-2

Li, M. P-1-1

Li, Q. P-4-2

Li, X. P-4-2

Li, Z. O-2-4

Li'an, T. P-3-1

Lijuan, F. P-3-1

Lin, H. P-4-5

Lin, L.-J. O-5-5

Lin, Y. P-4-4

Liu, L. P-1-1

Liu, L. P-3-4

Liu, W. P-4-5, P-4-5

$\mathrm{Lu}, \mathrm{X}$. O-4-5

Lv, H. P-1-1

Lv, S. P-1-1

Ma, T. O-5-5

Ma, Y. O-5-5

Machida, H. P-3-5

Matsui, H. O-3-2

Matsuoka, R. O-4-1

Matsushima, K. O-2-1

Matsuzaki, J. O-1-2

Mei-hua, X. P-4-6

Mesbah Uddin, A.M. O-4-4

Min, J.H. P-2-2

Min, J. P-4-1

Ming-yu, G. P-5-5

Miwa, H. O-1-3

Mizokami, Y. O-3-2

Morimoto, K. P-3-5

Moriwaki, T. O-3-2

Moriyama, I. O-4-4

Nagano, Y. O-3-2

Naito, Y. O-5-3

Nakae, Y. P-3-2

Nakaji, K. P-3-2

Nakao, K. O-2-1

Nakase, Y. O-4-1
Nakayama, T. O-2-1

Nam, S.Y. O-5-4

Narasaka, T. O-3-2

Ni, J. P-5-3

Nishishita, M. P-3-5

Noguchi, A. P-3-5

Ock, C.Y. O-2-2

Ohnita, K. O-2-1

Oka, A. O-4-4

Okazaki, H. P-3-5

Oshima, T. O-1-3

Ouyang, H. P-1-5

Oyama, T. O-1-1

Paek, N.-S. O-2-2

Park, C.H. P-1-2, P-2-2

Park, D.K. P-2-5

Park, J.C. P-1-2, P-2-2

Park, Y.S. O-3-3, P-2-3

Piao, H. P-2-4

Qi, Z. O-4-5

Qian, L. P-1-6

Qing-Gong, Y. O-5-1

Rani, A. O-3-6, O-3-5

Rigoutsos, I. O-5-4

Saito, Y. O-1-2

Sakagami, J. O-5-3

Shan, J. O-1-3

Shi, R. P-5-3

Shimokawa, O. O-3-2

Shin, S. P-1-2, P-2-2

Shin, S.K. P-1-2, P-2-2

Shinomura, Y. O-2-5

Simadibrata, M. O-3-5, O-3-6

Sogawa, M. P-3-5

Song, H.J. O-3-3, P-2-3

$\mathrm{Su}, \mathrm{T}$. O-2-4

Sugimori, S. P-3-5

Sun, M. P-2-6

Suzuki, H. O-1-2, O-3-2

Suzumura, S. P-3-2

Syam, A.F. O-3-5, O-3-6

Tada, Y. O-4-4

Takagi, T. O-5-3

Takahashi, A. O-1-1

Takeshima, F. O-2-1

Takeuchi, K. O-4-1

Tanigawa, T. P-3-5

\section{KARGER}

(C) 2012 S. Karger AG, Basel

Fax +4161306 1234

E-Mail karger@karger.ch

www.karger.com

Accessible online at:

www.karger.com/dig 
Tian, G. P-5-2

Tian, Y. P-5-2

Ting, L. P-1-6

Togawa, M. O-1-3

Tominaga, K. P-3-5

Tsugawa, H. O-1-2

Uchiyama, K. O-5-3

Wanandi, S.I. O-3-6

Wang, S. P-5-1

Wang, S. P-3-4

Watanabe, K. P-3-5

Watanabe, M. O-1-2

Watanabe, T. P-3-5
Watari, J. O-1-3

Wei-jian, Y. P-1-6

Wu, W. P-4-2

Xiang-yu, D. P-4-6

Xiao-mei, Z. P-1-3

Xin-hua, L. P-1-3, P-1-6

$\mathrm{Xu}, \mathrm{M}$. P-4-2

$\mathrm{Xu}, \mathrm{S} . \mathrm{P}-5-3$

$\mathrm{Xu}, \mathrm{X} . \mathrm{P}-2-4$

Xuemei, Z. P-4-3

Yagi, N. O-5-3

Yamagami, H. P-3-5

Yamaguchi, N. O-2-1
Yamamoto, T. P-1-4

Yang, C. P-5-1

Yang, L. P-5-1

Yasuda, H. O-5-3

Yiyou, Z. P-3-1

Yoshida, N. O-5-3

Yoshikawa, T. O-5-3

Yu, S. P-5-2

Yuki, T. O-4-4

Zeng, M. P-3-4

Zhang, G. P-4-2

Zhang, L. P-5-2

Zhang, Q. P-4-5

Zhaohui, W. P-4-3
Zheng, C.-Q. O-5-5

Zhong, L. P-5-1

Zhongliang, H. P-3-1

Zhou, Z. P-4-5

Zhu, H. P-5-3 